\title{
Understanding the contributions of aerosol properties and parameterization discrepancies to droplet number variability in a global climate model
}

\author{
R. Morales Betancourt ${ }^{1}$ and A. Nenes ${ }^{1,2}$ \\ ${ }^{1}$ School of Earth and Atmospheric Sciences, Georgia Institute of Technology, Atlanta, Georgia, USA \\ ${ }^{2}$ School of Chemical and Biomolecular Engineering, Georgia Institute of Technology, Atlanta, Georgia, USA \\ Correspondence to: A. Nenes (athanasios.nenes@gatech.edu)
}

Received: 24 October 2013 - Published in Atmos. Chem. Phys. Discuss.: 2 December 2013

Revised: 18 March 2014 - Accepted: 21 March 2014 - Published: 14 May 2014

\begin{abstract}
Aerosol indirect effects in climate models strongly depend on the representation of the aerosol activation process. In this study, we assess the process-level differences across activation parameterizations that contribute to droplet number uncertainty by using the adjoints of the AbdulRazzak and Ghan (2000) and Fountoukis and Nenes (2005) droplet activation parameterizations in the framework of the Community Atmospheric Model version 5.1 (CAM5.1). The adjoint sensitivities of $N_{\mathrm{d}}$ to relevant input parameters are used to (i) unravel the spatially resolved contribution of aerosol number, mass, and chemical composition to changes in $N_{\mathrm{d}}$ between present-day and pre-industrial simulations and (ii) identify the key variables responsible for the differences in $N_{\mathrm{d}}$ fields and aerosol indirect effect estimates when different activation schemes are used within the same modeling framework. The sensitivities are computed online at minimal computational cost. Changes in aerosol number and aerosol mass concentrations were found to contribute to $N_{\mathrm{d}}$ differences much more strongly than chemical composition effects. The main sources of discrepancy between the activation parameterizations considered were the treatment of the water uptake by coarse mode particles, and the sensitivity of the parameterized $N_{\mathrm{d}}$ accumulation mode aerosol geometric mean diameter. These two factors explain the different predictions of $N_{\mathrm{d}}$ over land and over oceans when these parameterizations are employed. Discrepancies in the sensitivity to aerosol size are responsible for an exaggerated response to aerosol volume changes over heavily polluted regions. Because these regions are collocated with areas of deep clouds, their impact on shortwave cloud forc-
\end{abstract}

ing is amplified through liquid water path changes. The same framework is also utilized to efficiently explore droplet number uncertainty attributable to hygroscopicity parameter of organic aerosol (primary and secondary). Comparisons between the parameterization-derived sensitivities of droplet number against predictions with detailed numerical simulations of the activation process were performed to validate the physical consistency of the adjoint sensitivities.

\section{Introduction}

The impact of atmospheric aerosols on the energy budget of the earth and on cloud microphysical properties is a major contributor to climate prediction uncertainty and estimates of anthropogenic climate change (Intergovernmental Panel on Climate Change, 2007). Due in part to the computational complexity of the models used for climate projections, quantification of uncertainty has often been reported in terms of model diversity (e.g., Kinne et al., 2006; Quaas et al., 2009; Myhre et al., 2013), rather than by analyzing the uncertainty associated with specific parameters and processes. This approach, although useful, does not always allow the identification of the process-level differences causing these discrepancies. As a result, the identification of the specific parameters and processes that contribute the most to the uncertainty in simulated aerosol-cloud interactions remains elusive.

Atmospheric aerosols can influence the planetary radiative balance by scattering and absorbing light or by modifying the optical properties of clouds by serving as nuclei for cloud 
droplets and ice crystals. The latter is known as aerosol indirect effect (AIE). In order to make quantitative estimates of AIE in global circulation models, it is necessary to realistically represent both the availability of atmospheric aerosol that can act as cloud condensation nuclei $(\mathrm{CCN})$ as well as the activation process by which a subset of $\mathrm{CCN}$ activate into cloud droplets.

Because the ability of an aerosol particle to act as a $\mathrm{CCN}$ depends strongly on its size and chemical composition (e.g., McFiggans et al., 2006), accurately simulating the availability of $\mathrm{CCN}$ requires knowledge of the aerosol size distribution and the mixing state of the different species in the aerosol phase. For this reason, state-of-the-art climate models include either modal or sectional representations of aerosol size distributions, and have conservation equations for the number and mass concentration for the main aerosol species, including sulfate, sea salt, dust, and carbonaceous aerosols (e.g., Stier et al., 2005; Dentener et al., 2011; Liu et al., 2012). Inclusion of detailed aerosol modules, which allows a more physically consistent description of atmospheric aerosols, has increased the computational burden of climate models and introduced more, sometimes uncertain, parameters to describe the extra processes. For instance, aerosol species that are emitted directly, such as black carbon (BC), primary organic matter (POM) or sulfate aerosol, for which emission inventories provide their mass fluxes to the atmosphere, require information on the size distribution of the emitted particles. The assumed distribution, which is often uncertain or unknown, largely controls the number concentration of emitted particles, playing an important role on the simulated CCN concentrations (e.g., Adams and Seinfeld, 2003; Pierce and Adams, 2009).

The incorporation of carbonaceous aerosols and their inclusion in AIE estimates has been an important part of Global Climate Model (GCM) development. Owing to the plethora of compounds involved in the makeup of organic aerosols, the parameters describing their hygroscopicity are less well constrained than those of inorganic aerosol species (Petters and Kreidenweis, 2007). Uncertainty in these parameters can affect AIE estimates, since organic species are known to contribute an important fraction of atmospheric aerosols and can affect the number concentration and hygroscopicity of accumulation mode aerosol (e.g., Novakov and Penner, 1993; Jimenez et al., 2009). Overall, the apportionment of uncertainty is sometimes obscured by the increased complexity of climate models with detailed aerosol-cloud interactions.

A variety of methods to assess the problem of uncertainty in CCN number have been employed. Evaluation of the impact of parametric uncertainty in climate model simulations has been typically done by performing model integrations with one parametric value perturbed to then do a finite difference computation. Such an approach has been used, for example, to quantify the sensitivity of $\mathrm{CCN}$ and cloud droplet number (CDNC) to the assumed hygroscopicity of secondary organic aerosol (Liu and Wang, 2010). Many studies have used similar approaches to asses the importance of the assumed split between primary and secondary organic emissions (e.g., Trivitayanurak and Adams, 2014).

Another approach used to assess the problem of uncertainty in aerosol-cloud interactions consists of running an ensemble of simulations with perturbed parameters to construct a Bayesian process emulator (e.g., Lee et al., 2011). This approach has been explored in variance-based sensitivity analyses to establish a hierarchy of parameters based on their contribution to $\mathrm{CCN}$ number uncertainty using a chemical transport model with detailed aerosol microphysics (e.g., Lee et al., 2012, 2013a). These studies have shown that parameters related to emissions carry a large proportion of the uncertainty in CCN concentrations (Lee et al., 2013a), since these parameters have a direct impact on the CCN population. The statistical approach has also been used in a GCM framework to evaluate the impact of aerosol parameter in the radiative budget at the top of the atmosphere (Zhao et al., 2013). These studies have pointed out the importance of accurate emission inventories as well as the parameters describing emission size distributions and the hygroscopicity of organic species. Nevertheless, this approach requires a large number of model integrations to build an accurate emulator within a given parameter space, with the number of runs growing together with the dimensionality of the parameter space.

However, the availability of $\mathrm{CCN}$ alone is not enough to describe the link between aerosol properties and cloud microphysics, and is therefore insufficient to compute AIE estimates. Aerosol activation is a dynamical process that involves the competition between the sink of water vapor (represented by the $\mathrm{CCN}$ availability) as well as the dynamical forcing provided by cloud-scale vertical motions. Both these factors are necessary to compute the cloud droplet number concentration. Several physically based activation schemes are used in climate models (e.g., Abdul-Razzak and Ghan, 2000; Fountoukis and Nenes, 2005; Ming et al., 2006; Shipway and Abel, 2010). These schemes require the knowledge of the CCN availability at a given water supersaturation $s$, which can be determined from the aerosol size distribution and chemical composition. Different activation parameterizations implemented in the same modeling framework can produce important differences in the radiative forcing even when the physics they represent are very similar (Ghan et al., 2011). The uncertainty associated with the activation scheme used should also be evaluated and quantified.

The adjoint sensitivity approach is an efficient method to investigate process sensitivity to input parameters in complex models. The method involves the construction of numerical routines that compute, with analytical precision, the first-order derivative of a process parameterization with respect to a set of input variables. The computation of sensitivities is achieved without the need of invoking the subroutine several times to perform finite difference computations. The adjoint-sensitivity approach has been recently used in 
different applications involving aerosol activation schemes. Karydis et al. (2012a) used the adjoint approach to compute the impact of aerosol precursor emissions on cloud droplet number (CDNC) over North America using the GEOS-Chem chemical transport model. Saide et al. (2012) used the adjoint of an activation scheme in the WRF model, coupled with satellite-derived retrievals of CDNC to infer aerosol concentrations below clouds, inaccessible to satellite sensors. To our knowledge, this tool has yet to be implemented in a GCM framework.

Here we report the implementation of the adjoint sensitivities of commonly used, physically based activation parameterizations in the Community Atmosphere Model version 5.1 (CAM5.1). We compare the sensitivity of droplet number to aerosol characteristics to determine the variables responsible for the discrepancies in CDNC among the parameterizations considered here. The information provided by firstorder derivatives is also used to elucidate the spatially resolved impact of parametric uncertainty, illustrated here with the hygroscopicity of secondary and primary organic aerosol.

The paper is organized as follows. In the first section, we describe the implementation of the adjoint sensitivities in the CAM-5.1 AGCM. The second section studies the different responses of the FN-adjoint and ARG-adjoint under identical model conditions, and identifies the underlying cause for their divergent response. The final two sections are devoted to the application of the adjoint in the quantification of organic aerosol parametric uncertainty, by exploring the adjoint sensitivity to the assumed hygroscopicity of secondary organic aerosol (SOA) and POM.

\section{Model framework description}

\subsection{AGCM simulations with CAM5.1}

Simulations were performed with the Community Atmosphere Model version 5.1 (CAM5.1) atmospheric general circulation model (AGCM). CAM is the atmospheric component of the Community Earth System Model (CESM1.0), and is described in full detail on http://www.cesm.ucar.edu/ models/cesm $1.0 / \mathrm{cam} /$. Here we focus on the description of the physical processes most directly involved in the aerosolcloud linkage.

The aerosol module of CAM5.1, which provides the aerosol characteristics necessary for the calculation of droplet activation, is the three-mode version of the modal aerosol module (MAM3) (Liu et al., 2012). This aerosol module considers eight aerosol species (sulfate, ammonium, nitrate, primary organic matter (POM), secondary organic aerosol (SOA), black carbon, sea salt, and dust) partitioned into three log-normally distributed modes (accumulation, Aitken, and coarse modes). The species in each mode are assumed to be internally mixed. The geometric standard deviation $\sigma_{\mathrm{g}_{i}}$ of each mode is prescribed, but aerosol number concentration $\left(n_{\mathrm{a}_{i}}\right)$ and mode diameter $\left(d_{\mathrm{g}_{i}}\right)$ for each mode are allowed to vary to accommodate the corresponding mass. Characteristics of the MAM3 aerosol are summarized in Table 1 . The cloud-scale vertical velocity used to drive the activation process is computed from the turbulent kinetic energy,

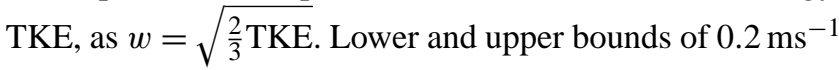
and $10 \mathrm{~ms}^{-1}$ respectively are imposed on $w$. The aerosol direct and indirect effects using the default configuration of MAM3 have been studied in detail by Ghan et al. (2012). The aerosol in CAM interacts with stratiform clouds using the double moment cloud microphysics scheme of Morrison and Gettelman (2008). The aerosol activation process is the source term for the grid-box CDNC equation balance. The fraction of aerosols activated into cloud droplets can be removed by wet scavenging or regenerated to the interstitial aerosol population after cloud evaporation.

The simulation results reported here were obtained by integrating the model for a period of $6 \mathrm{yr}$, using climatological sea surface temperature (SST) corresponding to year 2000. Greenhouse gases concentrations where also set to values corresponding to year 2000. Annual and seasonal averages correspond to the last $5 \mathrm{yr}$ of integration, with the first year discarded as spin-up. Simulations were performed with present-day (year 2000) and pre-industrial (year 1850) emissions of aerosols, aerosol precursors, and atmospheric oxidants from the Lamarque et al. (2010) inventory. Injection heights and emission sizes follow Dentener et al. (2006). To isolate the impact of aerosol load changes between presentday and pre-industrial times, the concentration of greenhouse gases was maintained at present-day levels.

\subsection{Adjoint sensitivities of $N_{\mathrm{d}}$ to aerosol properties}

We consider the sensitivity of $N_{\mathrm{d}}$ to a set of 10 variables which include the cloud-scale vertical velocity, $w$; aerosol number concentration per mode, $n_{\mathrm{a}_{i}}$; the mode diameter, $d_{\mathrm{g}_{i}}$; and the hygroscopicity parameter, $\kappa_{\mathrm{a}_{i}}$, for each of the three lognormal modes. The hygroscopicity parameter accounts for the effect of the chemical composition in the water uptake ability of aerosol particles. Because each mode is assumed internally mixed, $\kappa_{\mathrm{a}_{i}}$ is given by the volume-weighted average of the hygroscopicity parameter of each constituent species (Petters and Kreidenweis, 2007) (Table 1), i.e.,

$\kappa_{\mathrm{a}_{i}}=\sum_{\alpha \in i} v_{\alpha, i} \kappa_{\alpha}$,

where $v_{\alpha, i}$ is the volume fraction of species $\alpha$ in the $i$ th mode. Greek subindices will be used throughout the manuscript to indicate aerosol constituents, while latin subindices are reserved for aerosol modes. The adjoint sensitivity of these parameterizations was implemented such that each call to the activation routine produces $N_{\mathrm{d}}$, together with the set of derivatives $\partial N_{\mathrm{d}} / \partial \chi_{j}$, to each of the 10 parameters $\chi_{j}$. Since $d_{\mathrm{g}_{i}}$ is not an independent variable, but is computed from the volume $\left(v_{\mathrm{a}_{i}}\right)$ and number concentration of each mode $\left(n_{\mathrm{a}_{i}}\right)$, 
Table 1. Aerosol species and size distribution parameters in MAM3 used as input for the cloud droplet number activation parameterizations. $d_{\mathrm{g}_{i}}$ is the geometric mean diameter $(\mu \mathrm{m})$, and $\sigma_{\mathrm{g}_{i}}$ the geometric standard deviation for each mode $i$ (Liu et al., 2012).

\begin{tabular}{llcccc}
\hline Aerosol mode & Aerosol species & $\begin{array}{c}\text { Hygroscopicity } \\
\kappa_{\alpha}\end{array}$ & $\begin{array}{c}\text { Density } \\
\left(\mathrm{g} \mathrm{cm}^{-3}\right)\end{array}$ & $\sigma_{\mathrm{g}_{i}}$ & $\begin{array}{c}d_{\mathrm{g}_{i}} \text { range } \\
(\mu \mathrm{m})\end{array}$ \\
\hline Accumulation & Sulfate & 0.507 & 1.77 & 1.8 & $0.053-0.44$ \\
& POM & 0.10 & 1.00 & & \\
& SOA & 0.14 & 1.00 & & \\
& Black carbon & $1 \times 10^{-10}$ & 1.70 & & \\
& Sea salt & 1.160 & 1.90 & & \\
& Dust & 0.068 & 2.60 & & \\
\hline \multirow{2}{*}{ Aitken } & Sulfate & 0.507 & 1.77 & 1.6 & $0.0087-0.052$ \\
& SOA & 0.14 & 1.00 & & \\
& Sea salt & 1.160 & 1.90 & & \\
\hline \multirow{2}{*}{ Coarse } & Sulfate & 0.507 & 1.77 & 1.8 & $1.0-4.0$ \\
& Sea salt & 1.160 & 1.90 & & \\
& Dust & 0.068 & 2.60 & & \\
\hline
\end{tabular}

the adjoint sensitivities are expressed in terms of the independent variables $v_{\mathrm{a}_{i}}$ and $n_{\mathrm{a}_{i}}$ alone.

The parameterizations considered in this study include two within the ARG parameterization framework (Abdul-Razzak and Ghan, 2000; Ghan et al., 2011), and two from within the FN parameterization framework (Fountoukis and Nenes, 2005; Barahona et al., 2010). We used the default activation scheme used in CAM5.1, which is the ARG parameterization (Abdul-Razzak and Ghan, 2000), and a revised version, $\mathrm{ARG} \alpha$, that includes the effects of the mass accommodation coefficient in the condensation process (Ghan et al., 2011). When the mass accommodation coefficient $\left(\alpha_{c}\right)$ is unity, the $\mathrm{ARG} \alpha$ parameterization reduces to the the default ARG parameterization. Similarly, we used the FN activation scheme (Fountoukis and Nenes, 2005), and an updated version, FNIL, that includes terms to better account for the water uptake by inertially limited CCN (Barahona et al., 2010). These parameterizations are based on a similar set of physical principles and assumptions (Ghan et al., 2011).

There are methodological differences in the calculation of the sensitivities for each parameterization framework. In the case of ARG and ARG $\alpha$, sensitivities can be computed analytically, as shown by Rissman et al. (2004), and this is the approach used in this work (see Appendix A). The FN and FN-IL parameterizations use instead a set of numerical routines to compute $N_{\mathrm{d}}$, which prevents the use of explicit equations. Therefore, efficient computation of the sensitivities in the FN framework required the development of a corresponding adjoint code. For this, we implemented the newly developed adjoint sensitivity of the FN and FN-IL (Karydis et al., 2012b), which uses automatic differentiation software to build the necessary subroutines.

\section{Results}

\subsection{Overview of the simulations}

Among the activation parameterizations included in this study, ARG $\alpha, F N$, and FN-IL include the effect of noncontinuum effects in the condensation process through an explicit dependence on the accommodation coefficient, $\alpha_{\mathrm{c}}$ (Pruppacher and Klett, 1997). For the simulations performed with those parameterizations, the value of $\alpha_{\mathrm{c}}$ was set equal to 0.1 , which is within the observed range of $\alpha_{\mathrm{c}}$ in various locations (Raatikainen et al., 2013). Furthermore, it has been shown that $N_{\mathrm{d}}$ is not sensitive to $\alpha_{\mathrm{c}}$ in the range of 0.1 to 1. Simulations with the ARG parameterization (equivalent to ARG $\alpha$ with $\alpha_{\mathrm{c}}=1$ ) are included for reference, since this is the activation scheme used in the release version of CAM5.1. A summary of the model integrations performed is included in Table 2.

Annual mean values for radiation and cloud parameters are shown in Table 3. The strongest shortwave cloud forcing difference between PD and PI simulations $(\triangle \mathrm{SWCF})$ is observed for simulations with $\mathrm{ARG} \alpha$. The larger $\triangle \mathrm{SWCF}$ associated with ARG $\alpha$ is likely due to the large difference in the global mean liquid water path.

The annual mean in-cloud droplet number concentrations, $N_{\mathrm{d}}$, for the fifth model layer $(930 \mathrm{hPa})$ are shown in Fig. 1 for the present-day simulation. This pressure level was chosen because it has the largest liquid cloud cover, and is representative of the results for the pressure levels in the column with liquid clouds. Figure 1 also shows the change in $N_{\mathrm{d}}$ between present-day and pre-industrial simulations. These maps exhibit the expected patterns of increased CDNC over continental regions, with a particularly large increase in $N_{\mathrm{d}}$ over Southeast Asia. The marked decrease in CDNC over Southeast US, central South America, and northern Australia 


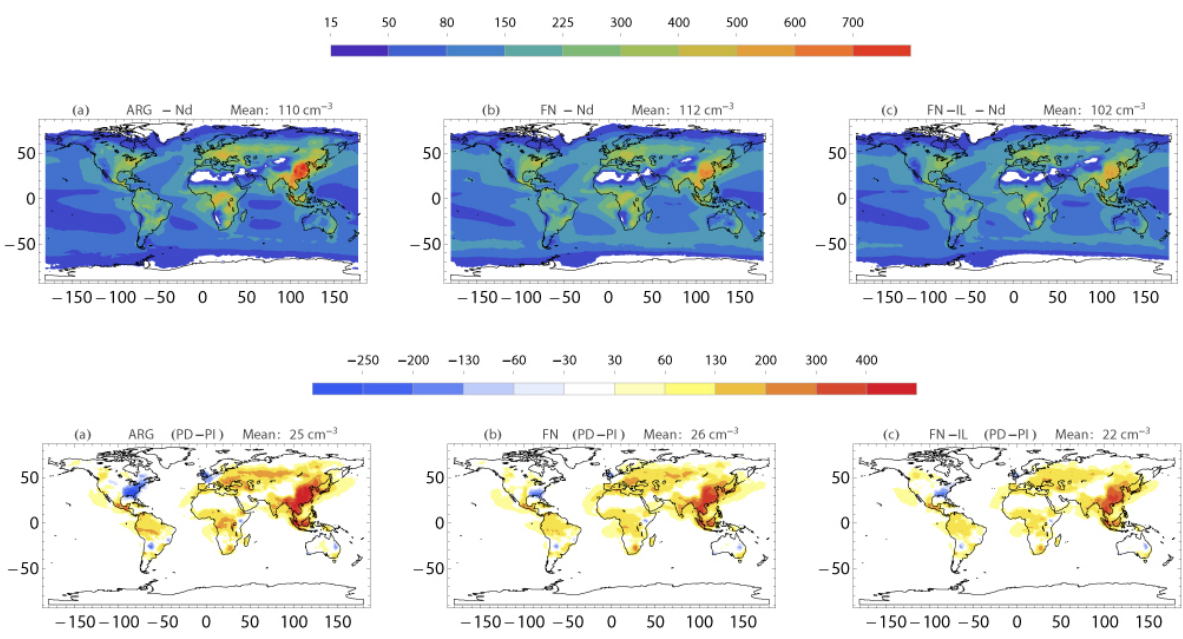

Fig. 1. Annual mean in-cloud droplet number concentration, $N_{\mathrm{d}}\left(\mathrm{in}_{\mathrm{cm}}^{3} \mathrm{~cm}^{-3}\right)$, at the $930 \mathrm{mb}$ pressure level predicted for (a) ARG $\alpha-\mathrm{PD}$, (b) FN-PD, and (c) FN-IL-PD. The lower panels show the difference in $\left(\Delta N_{\mathrm{d}}\right)$ between present-day (PD) and pre-industrial emissions (PI).

Table 2. Summary of simulations.

\begin{tabular}{llcc}
\hline Experiment ID & Activation parameterization & $\begin{array}{c}\text { Aerosol } \\
\text { emissions }\end{array}$ & $\begin{array}{c}\text { Accommodation } \\
\text { coefficient }\end{array}$ \\
\hline ARG-PD & Abdul-Razzak and Ghan (2000) & Year 2000 & N/A \\
ARG-PI & Abdul-Razzak and Ghan (2000) & Year 1850 & N/A \\
ARG $\alpha$-PD & Ghan et al. (2011) & Year 2000 & $\alpha_{\mathfrak{c}}=0.1$ \\
ARG $\alpha$-PI & Ghan et al. (2011) & Year 1850 & $\alpha_{\mathfrak{c}}=0.1$ \\
FN-PD & Fountoukis and Nenes (2005) & Year 2000 & $\alpha_{\mathrm{c}}=0.1$ \\
FN-PI & Fountoukis and Nenes (2005) & Year 1850 & $\alpha_{\mathrm{c}}=0.1$ \\
FN-IL-PD & Barahona et al. (2010) & Year 2000 & $\alpha_{\mathrm{c}}=0.1$ \\
FN-IL-PI & Barahona et al. (2010) & Year 1850 & $\alpha_{\mathrm{c}}=0.1$ \\
\hline
\end{tabular}

has been observed in other studies, pointing to changes in biomass burning emissions as the cause (Wang et al., 2011). This feature arises from the emissions inventory used, in particular, the assumed size of the aerosol emitted, and has an important impact in both direct (e.g., Lee et al., 2013b) and indirect effects (e.g., Wang et al., 2011; Bauer and Menon, 2012).

The $N_{\mathrm{d}}$ fields in Fig. 1 show also some noticeable differences across different parameterizations. Global mean $N_{\mathrm{d}}$ produced with ARG $\alpha$ is slightly larger than those for $\mathrm{FN}$ and FN-IL, but droplet number concentrations over oceans show the opposite trend, being lower for FN and FN-IL compared to $\mathrm{ARG} \alpha$. For present-day aerosol emissions, simulations with ARG $\alpha$ have more numerous and smaller cloud droplets over land than simulations with FN or FN-IL. This difference is especially noticeable over the heavily polluted region of Southeast Asia. As a consequence, the annual mean cloud droplet effective radius, $r_{\mathrm{e}}$, in ARG $\alpha$-PD is $3.5 \%$ smaller over continents when compared to FN-PD, while the $N_{\mathrm{d}}$ is $10 \%$ larger over continents. This trend is reversed over oceanic regions, where the relative difference in $r_{\mathrm{e}}$ is $1 \%$ larger for $\mathrm{ARG} \alpha$ and $N_{\mathrm{d}}$ is $15 \%$ smaller. The reason for these differences across parameterizations will be further discussed in Sect. 3.3.

\subsection{Sensitivity of ARG/ARG $\alpha$ and FN/FN-IL schemes in CAM}

The sensitivities $\partial N_{\mathrm{d}} / \partial \chi_{j}$ were computed at each time step during model integration, and annual mean in-cloud sensitivities summarized in Table 4. The spatial distribution of the annual mean in-cloud sensitivity of $N_{\mathrm{d}}$ to aerosol number and hygroscopicity parameter are shown in Figs. 2 and 3, respectively.

Sensitivity of $N_{\mathrm{d}}$ for the Aitken mode to both $n_{\mathrm{a}_{i}}$ and $\kappa_{\mathrm{a}_{i}}$ is negligible, indicating that $N_{\mathrm{d}}$ is only weakly dependent on these parameters. This is expected, given that their size generally limits their contribution to the $\mathrm{CCN}$ concentration. Their size also limits the amount of water vapor they deplete during cloud formation, therefore only weakly impacting the maximum supersaturation. All the parameterizations considered consistently reflect this. The spatial distribution and magnitude of $\frac{\partial N_{\mathrm{d}}}{\partial n_{\mathrm{a}_{i}}}$ and $\frac{\partial N_{\mathrm{d}}}{\partial \kappa_{\mathrm{a}_{i}}}$ for accumulation mode aerosol are also in good agreement across parameterizations 
Table 3. Annual global mean for selected radiation parameters and cloud properties: shortwave cloud forcing (SWCF), longwave cloud forcing (LWCF), liquid and ice water path (LWP and IWP respectively), total precipitation (PRECT), and column droplet number concentration (CDNUMC). The difference of these variables between PD and PI simulations, as well as for the total cloud forcing $\triangle \mathrm{CF}=$ $\Delta(\mathrm{SWCF}+\mathrm{LWCF})$, and the cloud top effective radius $\Delta r_{\mathrm{e}}$.

\begin{tabular}{|c|c|c|c|c|c|c|c|c|}
\hline & \multicolumn{2}{|c|}{ ARG } & \multicolumn{2}{|c|}{$\mathrm{ARG} \alpha$} & \multicolumn{2}{|c|}{ FN } & \multicolumn{2}{|c|}{ FN-IL } \\
\hline & PD & PI & PD & PI & PD & PI & PD & PI \\
\hline $\operatorname{SWCF}\left(\mathrm{Wm}^{-2}\right)$ & -51.85 & -49.86 & -53.38 & -51.13 & -54.05 & -52.00 & -53.71 & -51.70 \\
\hline $\operatorname{LWCF}\left(\mathrm{Wm}^{-2}\right)$ & 24.15 & 23.80 & 24.13 & 23.79 & 24.18 & 23.82 & 24.18 & 23.76 \\
\hline $\operatorname{LWP}\left(\mathrm{gm}^{-2}\right)$ & 44.38 & 40.73 & 47.26 & 42.82 & 47.77 & 43.57 & 47.37 & 43.45 \\
\hline $\operatorname{IWP}\left(\mathrm{g} \mathrm{m}^{-2}\right)$ & 17.81 & 17.76 & 17.68 & 17.65 & 17.74 & 17.55 & 17.74 & 17.55 \\
\hline PRECT $\left(\mathrm{mm} \mathrm{day}^{-1}\right)$ & 2.96 & 2.98 & 2.97 & 2.99 & 2.97 & 2.99 & 2.97 & 2.99 \\
\hline $\operatorname{CDNUMC}\left(10^{10} \mathrm{~m}^{-2}\right)$ & 1.33 & 0.96 & 1.85 & 1.30 & 1.83 & 1.28 & 1.67 & 1.20 \\
\hline$\Delta \mathrm{SWCF}\left(\mathrm{Wm}^{-2}\right)$ & \multicolumn{2}{|c|}{-2.00} & \multicolumn{2}{|c|}{-2.24} & \multicolumn{2}{|c|}{-2.05} & \multicolumn{2}{|c|}{-2.01} \\
\hline$\Delta \mathrm{CF}\left(\mathrm{Wm}^{-2}\right)$ & \multicolumn{2}{|c|}{-1.65} & \multicolumn{2}{|c|}{-1.90} & \multicolumn{2}{|c|}{-1.70} & \multicolumn{2}{|c|}{-1.60} \\
\hline$\triangle \mathrm{CDNUMC}(\%)$ & \multicolumn{2}{|c|}{38.6} & \multicolumn{2}{|c|}{42.6} & \multicolumn{2}{|c|}{42.7} & \multicolumn{2}{|c|}{39.0} \\
\hline$\Delta \mathrm{LWP}(\%)$ & \multirow{2}{*}{\multicolumn{2}{|c|}{$\begin{array}{r}8.97 \\
-2.2\end{array}$}} & \multicolumn{2}{|c|}{10.38} & \multicolumn{2}{|c|}{9.63} & \multicolumn{2}{|c|}{9.00} \\
\hline$\Delta r_{\mathrm{e}}(\%)$ & & & \multicolumn{2}{|c|}{-3.7} & \multicolumn{2}{|c|}{-4.1} & \multicolumn{2}{|c|}{-3.9} \\
\hline
\end{tabular}

Table 4. Annual mean sensitivities computed for the PD simulations. Fields are reported for the $930 \mathrm{mb}$ pressure level.

\begin{tabular}{llccccccccc}
\hline Sensitivity & Aerosol mode & \multicolumn{3}{c}{ ARG $\alpha$-PD } & \multicolumn{3}{c}{ FN-PD } & \multicolumn{3}{c}{ FN-IL-PD } \\
& & Land & Ocean & Global & Land & Ocean & Global & Land & Ocean & Global \\
\hline \multirow{3}{*}{$\partial N_{\mathrm{d}} / \partial n_{\mathrm{a}_{i}}(-)$} & Aitken & -0.009 & -0.002 & -0.004 & 0.019 & 0.037 & 0.031 & 0.015 & 0.020 & 0.018 \\
& Accumulation & 0.26 & 0.43 & 0.38 & 0.27 & 0.49 & 0.43 & 0.24 & 0.46 & 0.40 \\
& Coarse & -26.7 & -10.6 & -15.3 & 0.40 & 0.54 & 0.50 & -0.31 & -0.15 & -0.20 \\
\hline $\mathrm{d} N_{\mathrm{d}} / \mathrm{d} n_{\mathrm{a}}(-)$ & - & 0.19 & 0.18 & 0.18 & 0.22 & 0.31 & 0.28 & 0.19 & 0.25 & 0.24 \\
\hline \multirow{2}{*}{$\partial N_{\mathrm{d}} / \partial \kappa_{\mathrm{a}_{i}}\left(\mathrm{~cm}^{-3}\right)$} & Aitken & 9.06 & 8.19 & 7.92 & 8.41 & 10.62 & 9.96 & 7.29 & 9.23 & 8.66 \\
& Accumulation & 67.6 & 6.68 & 21.0 & 81.4 & 9.49 & 30.8 & 78.6 & 8.55 & 29.15 \\
& Coarse & -9.0 & -2.4 & -4.2 & 0.05 & 0.001 & 0.016 & -2.03 & -0.74 & -1.11 \\
\hline \multirow{2}{*}{$\partial N_{\mathrm{d}} / \partial d_{\mathrm{g}_{i}}\left(\mathrm{~cm}^{-3} \mu \mathrm{m}^{-1}\right)$} & Aitken & 433.7 & 545.7 & 512.7 & 284.8 & 561.2 & 479.2 & 249.8 & 507.7 & 431.9 \\
& Accumulation & 1125 & 167.3 & 449.5 & 482.8 & 78.0 & 198.1 & 466.8 & 65.86 & 183.7 \\
& Coarse & 0.0006 & 0.00008 & 0.0002 & 0.008 & 0.0005 & 0.003 & -0.75 & -1.43 & -1.23 \\
\hline$\partial N_{\mathrm{d}} / \partial w\left(\mathrm{~cm}^{-3} \mathrm{~m}^{-1} \mathrm{~s}\right)$ & - & 194.5 & 63.7 & 102.3 & 185.8 & 65.90 & 101.2 & 175.2 & 69.07 & 100.3 \\
\hline
\end{tabular}

(Fig. 2b, e, h and k). As expected, sensitivity of $N_{\mathrm{d}}$ to this population is strong and always positive, since they fall in the size range most appropriate for $\mathrm{CCN}$-active particles.

Discrepancies between ARG $\alpha, \mathrm{FN}$, and FN-IL in the sensitivity of $N_{\mathrm{d}}$ to coarse mode aerosol number and hygroscopicity are evident (Figs. 2 and 3), showing not only different magnitudes but in some cases also opposite signs. These large discrepancies arise in the treatment adopted in each scheme to describe the depletion of water vapor by the largest particles in the aerosol population.

From Table 4 it is clear that ARG $\alpha$ has the strongest negative sensitivity to coarse mode aerosol characteristics. The large negative response in the ARG $\alpha$ implies that the overall impact on $N_{\mathrm{d}}$ from the strong depletion of supersaturation by coarse mode particles (which depresses $s_{\max }$ ) largely offsets any contribution from coarse particles to the CCN population. On the other extreme, FN appears to strongly underestimate the water vapor depletion from coarse mode particles; therefore, changes to coarse mode aerosol do not impact $s_{\max }$ in a measurable way, while their large size and low $s_{\mathrm{c}}$ ensures their contribution to the droplet population. This is reflected in the sensitivity of FN to coarse mode aerosol number, which is positive, and slightly larger in magnitude than for the accumulation mode. An intermediate response is found when the FN-IL is used instead. This parameterization, which differs from FN in the treatment of the inertially limited CCN population, exhibits an often negative response to coarse mode aerosol, indicating a more physically consistent treatment of the water vapor depletion by this aerosol population. Careful validation of these sensitivities was performed by comparing them to detailed numerical simulations of the activation process (Appendix B). It was found that, of all formulations considered, the sensitivity to coarse mode aerosol is, on average, better captured by the FN-IL parameterization.

The same arguments can be extended to the sensitivity of $N_{\mathrm{d}}$ to $\kappa_{\mathrm{a}_{i}}$ and $d_{\mathrm{g}_{i}}$ of coarse mode particles. The weak water vapor depletion of coarse particles in FN leads to a negligible impact of the coarse mode $\kappa_{\mathrm{a}_{i}}$ and $d_{\mathrm{g}_{i}}$ on $N_{\mathrm{d}}$ (Table 4). Both ARG $\alpha$ and FN-IL, with a stronger depletion by coarse mode particles, are more sensitive to increases in the water uptake ability of this aerosol population. In both cases, a marked negative response is observed, in particular in areas where the coarse mode is dominated by dust, which has a very low hygroscopicity. The supersaturation depletion effect of coarse mode particles and their impact on $N_{\mathrm{d}}$ has been 


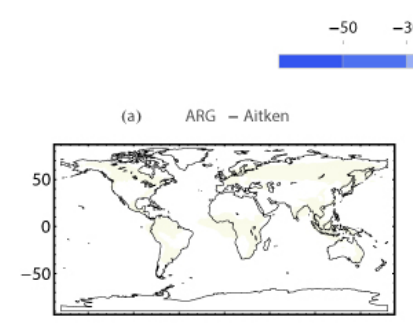

(d) ARG $\alpha$-Aitken

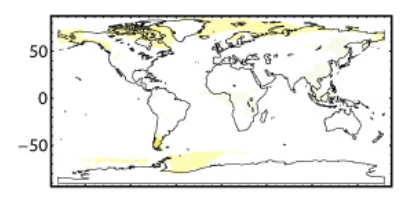

(g) FN - Aitken

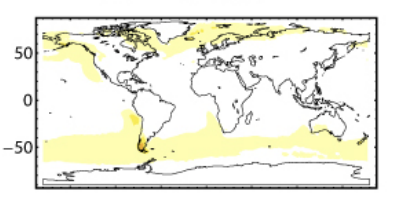

(j) FN-IL - Aitken

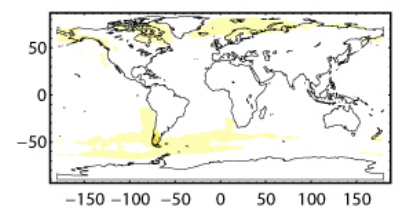

(b) ARG - Accumulation

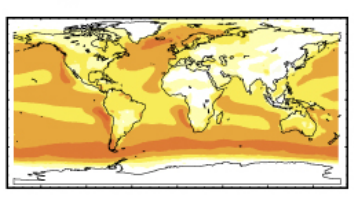

(e) ARG $\alpha$-Accumulation

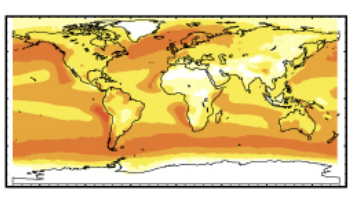

(h) $\mathrm{FN}-$ Accumulation

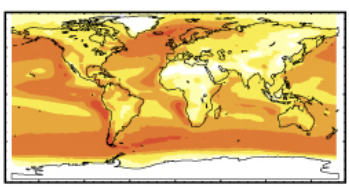

(k) $\quad \mathrm{FN}-\mathrm{IL}$ - Accumulation

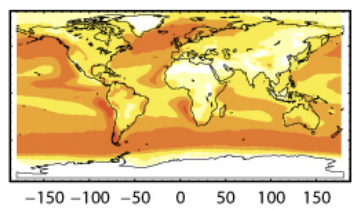

$0.55 \quad 0.7$

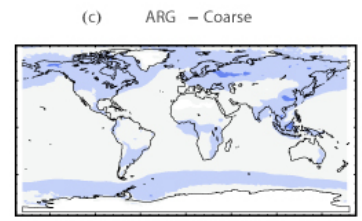

(f) ARG $\alpha$-coarse

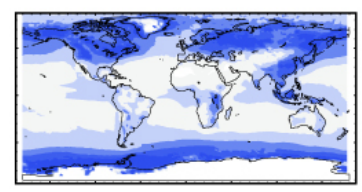

(i) $\quad \mathrm{FN}-$ Coarse

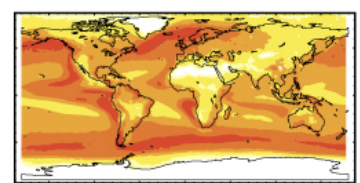

(l) FN-IL - Coarse

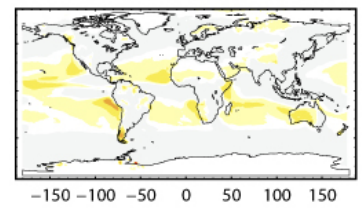

Fig. 2. Annual mean sensitivity to aerosol number concentration $\partial N_{\mathrm{d}} / \partial n_{\mathrm{a}_{i}}$. (a-c) Aitken, accumulation, and coarse modes in the ARG-PD simulation, (d-f) ARG $\alpha$-PD simulation, (g-i) FN-PD simulation, and (j-l) FN-IL-PD simulation.

observed and discussed previously (e.g., Ghan et al., 1998) in the framework of parcel model simulations, but the impact on global distributions of $N_{\mathrm{d}}$ had not been addressed before.

Table 4 also indicates a marked discrepancy in the sensitivity of $N_{\mathrm{d}}$ to geometric mean diameter, $\partial N_{\mathrm{d}} / \partial d_{\mathrm{g}_{i}}$, between $\mathrm{ARG} \alpha$ and FN or FN-IL. In particular, for Aitken and accumulation mode this sensitivity is higher for ARG $\alpha$ by a factor of 2 . Since $d_{\mathrm{g}_{i}}$ is derived from the volume and the number concentration for each mode, the derivatives of $N_{\mathrm{d}}$ with respect to $v_{\mathrm{a}_{i}}$ are given by

$\frac{\partial N_{\mathrm{d}}}{\partial v_{\mathrm{a}_{i}}}=\frac{d_{\mathrm{g}_{i}}}{3 v_{\mathrm{a}_{i}}} \frac{\partial N_{\mathrm{d}}}{\partial d_{\mathrm{g}_{i}}}$

Therefore, differences in the sensitivity to aerosol size directly impact the sensitivity to aerosol volume.

The overall sensitivity to aerosol number, $\mathrm{d} N_{\mathrm{d}} / \mathrm{d} n_{\mathrm{a}}$, often used measure of the strength of the AIE (e.g., Quaas et al., 2009), is also strongly affected by the above enhanced response to coarse mode particles. We define this quantity as the sensitivity of $N_{\mathrm{d}}$ to an overall increase in aerosol number that preserves the shape of the aerosol size distribution, i.e.,

$\frac{\mathrm{d} N_{\mathrm{d}}}{\mathrm{d} n_{\mathrm{a}}}=\sum_{i} \frac{\partial N_{\mathrm{d}}}{\partial n_{\mathrm{a}_{i}}} \frac{n_{\mathrm{a}_{i}}}{\left|n_{\mathrm{a}}\right|}$, where $\left|n_{\mathrm{a}}\right|^{2}=\sum_{i} n_{\mathrm{a}_{i}}^{2}$. The values of $\mathrm{d} N_{\mathrm{d}} / \mathrm{d} n_{\mathrm{a}}$ from the simulations indicate that aerosol activation over the vast majority of oceanic regions occurs under the "aerosol-limited" regime identified by Reutter et al. (2009), mainly due to relatively low aerosol loads.

The sensitivity from Eq. (3) is larger in the FN-PD experiment, with a global mean of 0.28 , than for simulations performed with the ARG $\alpha$ parameterization, which have a global mean $\mathrm{d} N_{\mathrm{d}} / \mathrm{d} n_{\mathrm{a}}$ of 0.19 , indicating a higher sensitivity to aerosol perturbations. This difference across parameterizations is largely explained by the negative sensitivity of ARG $\alpha$ to coarse mode particles, which strongly dampens the value of $\mathrm{d} N_{\mathrm{d}} / \mathrm{d} n_{\mathrm{a}}$ over marine environments (Table 4). This highlights the diverse contribution of each aerosol mode to $N_{\mathrm{d}}$, namely, the crucial importance of accumulation and coarse mode in determining the magnitude of $\mathrm{d} N_{\mathrm{d}} / \mathrm{d} n_{\mathrm{a}}$.

The higher sensitivity to aerosol number as expressed by Eq. (3) suggests that AIE should be stronger for simulations with FN and FN-IL compared to ARG $\alpha$. However, a number of fields in Table 3, including droplet number concentration and shortwave cloud forcing, are larger for $\mathrm{ARG} \alpha$ than for FN or FN-IL. This apparent inconsistency is resolved by realizing that $\mathrm{d} N_{\mathrm{d}} / \mathrm{d} n_{\mathrm{a}}$ does not capture the total sensitivity of CDNC to aerosol changes. In actuality, there are processes that cause an increase in $N_{\mathrm{d}}$ without involving a direct 


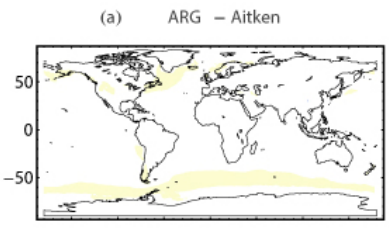

(d) ARG $\alpha$ - Aitken

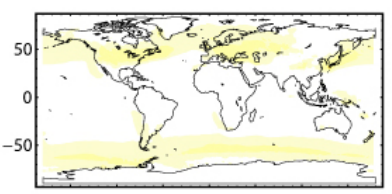

(g) FN - Aitken

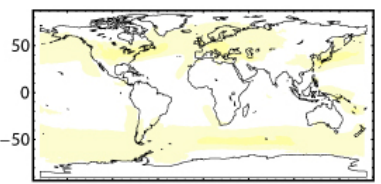

(j) $\mathrm{FN}-\mathrm{IL}-$ Aitken

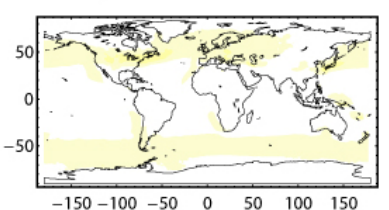

(b) ARG - Accumulation

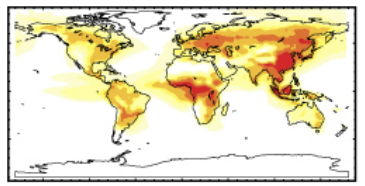

(e) ARG $\alpha$ - Accumulation

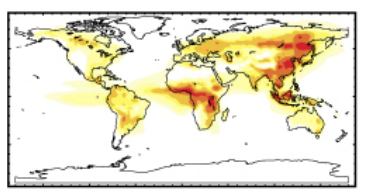

(h) $\quad \mathrm{FN}-$ Accumulation

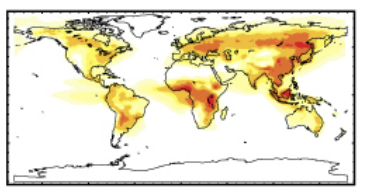

(k) $\quad \mathrm{FN}-\mathrm{IL}-$ Accumulation

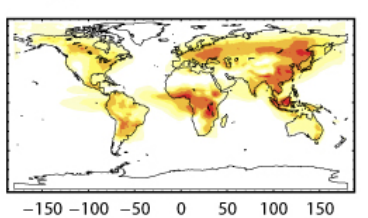

(c) ARG - Coarse

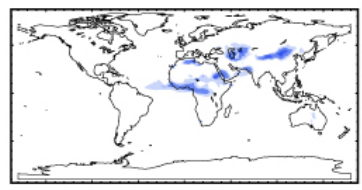

(f) ARG $\alpha-$ Coarse

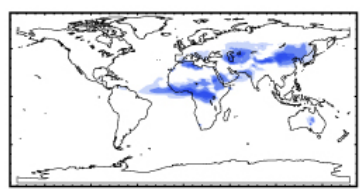

(i) $\mathrm{FN}-$ Coarse

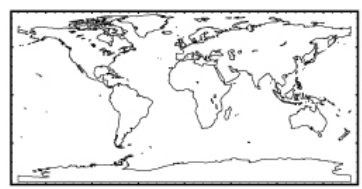

(1) $\mathrm{FN}-\mathrm{IL}-$ Coarse

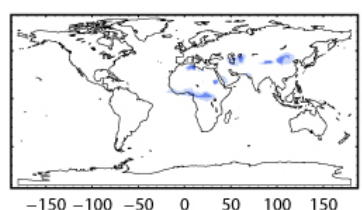

Fig. 3. Same as Fig. 2 but for aerosol hygroscopicity $\partial N_{\mathrm{d}} / \partial \kappa_{\mathrm{a}_{i}}\left(\right.$ in $\left.\mathrm{cm}^{-3}\right)$.

change in aerosol number concentration. For instance, condensation of sulfate or SOA on an aerosol population will cause the hygroscopicity and the volume of the aerosol to increase, without significantly changing $n_{\mathrm{a}}$. This suggests that the use of Eq. (3) as a metric for the strength of aerosol-cloud interactions does not capture the concurrent changes in $\mathrm{CCN}$ activity that are associated with increased hygroscopicity and size. In this regard, the different values of these sensitivities are important in understanding the simulated $N_{\mathrm{d}}$ fields with different parameterizations.

\subsection{Unraveling mass, number, and chemical composition contributions to $N_{\mathrm{d}}$}

The increase in aerosol emissions between PD and PI times has not only changed the total mass and number of atmospheric aerosol but has also modified its chemical composition. Due to the heterogeneity of aerosol precursor sources, changes in aerosol load and chemical composition have a marked regional imprint. For instance, the marked increase in anthropogenic sulfate aerosol over most continental areas of the Northern Hemisphere not only produces a much larger number concentration of aerosols but also promotes the hygroscopicity of continental aerosol after mixing with the background aerosol (composed mostly of POM, SOA,
$\mathrm{BC}$, and dust). The opposite trend is observed in the hygroscopicity of polluted marine aerosol as it is mixed with the sulfate aerosol outflow from continents.

The information provided by the adjoint sensitivities allows the apportionment of changes in $N_{\mathrm{d}}$ due to specific changes in either $n_{\mathrm{a}_{i}}, \kappa_{\mathrm{a}_{i}}$ or $v_{\mathrm{a}_{i}}$, and doing so in a spatially resolved manner. The approach we propose to achieve this apportionment consists of combining the change in aerosol number $\Delta n_{\mathrm{a}_{i}}$, aerosol volume $\Delta v_{\mathrm{a}_{i}}$ (proportional to the aerosol mass concentration changes), and mode hygroscopicity, $\Delta \kappa_{\mathrm{a}_{i}}$ between PD and PI simulations, with the adjoint sensitivity fields using a first-order approximation, i.e.,

$\left(\Delta N_{\mathrm{d}}\right)_{\chi_{i}}=\frac{\partial N_{\mathrm{d}}}{\partial \chi_{j}} \Delta \chi_{j}$

In this expression it is assumed that the first-order derivative $\partial N_{\mathrm{d}} / \partial \chi_{j}$ does not change considerably for PD and PI conditions. Even though small differences exist in the sensitivity computed at PD and PI conditions, the magnitude of $\Delta N_{\mathrm{d}}$ from Eq. (4) is largely controlled by the variation in the aerosol property $\Delta \chi_{j}$. Figure 4 shows the estimated change in $N_{\mathrm{d}}$ between PI and PD simulations that can be attributed to changes in the number $\left(\Delta N_{\mathrm{d}}\right)_{n_{\mathrm{a}}}$, volume $\left(\Delta N_{\mathrm{d}}\right)_{v_{\mathrm{a}}}$, and hygroscopicity, $\left(\Delta N_{\mathrm{d}}\right)_{\kappa_{\mathrm{a}}}$, of accumulation mode aerosol 


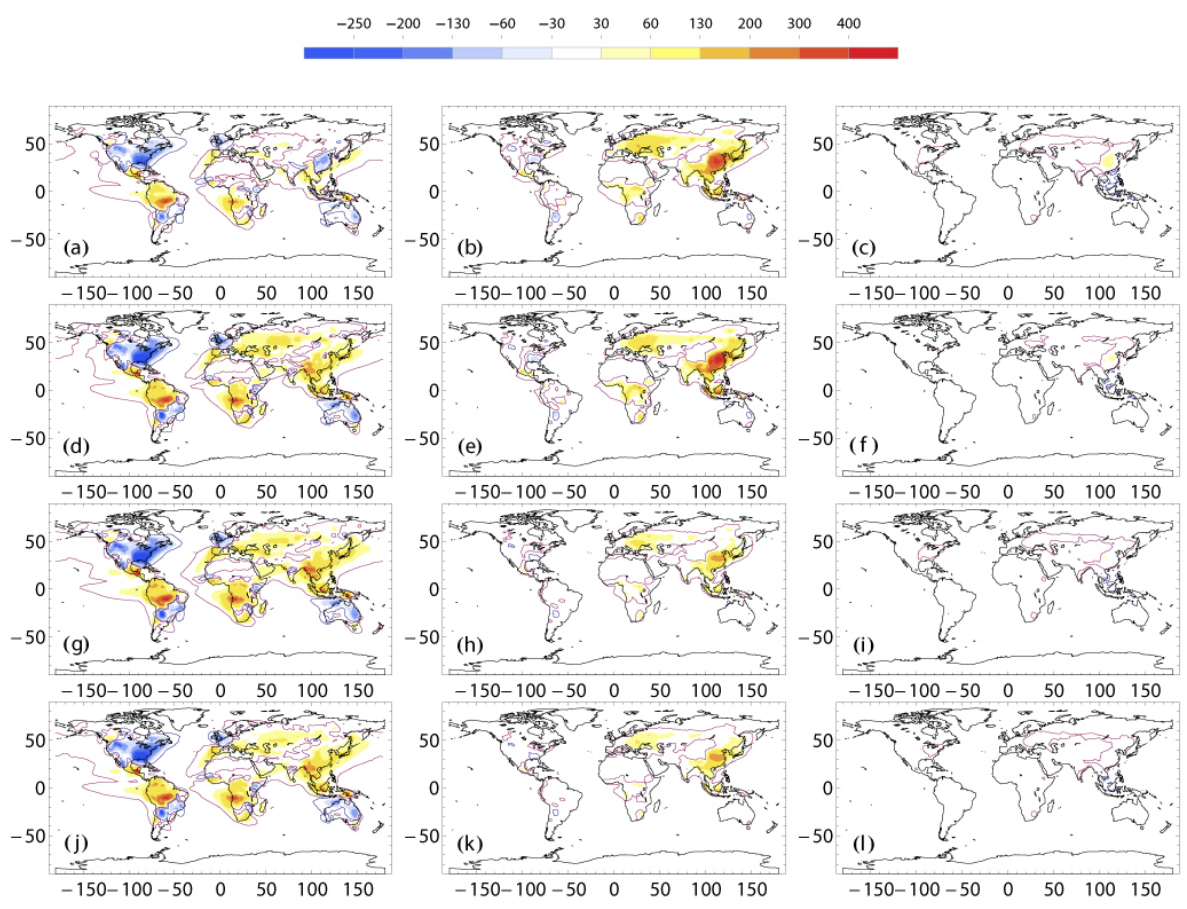

Fig. 4. Change in number of activated cloud droplets $\left(\mathrm{in}_{\mathrm{cm}}^{-3}\right.$ ) attributable to changes in accumulation mode aerosol properties. (a-c) $\delta N_{\mathrm{d}}$ due to change in aerosol number (a), aerosol volume (b), and aerosol hygroscopicity (c) for simulation with the ARG parameterization. (d-f) Same as above, but for the simulation using ARG $\alpha$. (g-i) Simulations with FN and (j-l) simulations with FN-IL.

using Eq. (4). For this calculation, the sensitivity was computed at present day. This analysis shows a negligible contribution from fine and coarse modes to $\Delta N_{\mathrm{d}}$ and is therefore not shown.

From Fig. 4 it is clear that the dominant contributor to $\Delta N_{\mathrm{d}}$ is the accumulation mode aerosol number, with a strong signal over continental regions. The spatial patterns and intensity of this field are very similar across parameterizations. Large areas of the globe exhibit a negative $\left(\Delta N_{\mathrm{d}}\right)_{n_{\mathrm{a}}}$, particularly over North America, and over the British Islands, as is also seen in Fig. 1. Since $\partial N_{\mathrm{d}} / \partial n_{\mathrm{a}_{i}}$ for accumulation mode aerosol is always positive, this reduction must be associated with a decrease in $n_{\mathrm{a}_{i}}$ from pre-industrial times over those areas. This trend occurs even though aerosol mass concentration has not decreased over those areas, supporting the idea that this is due to a decrease in primary emitted particles (Wang et al., 2011).

After $\Delta n_{\mathrm{a}}$, the next largest contributor to $\Delta N_{\mathrm{d}}$ is $\Delta v_{\mathrm{a}}$, i.e., the change in total aerosol volume (Fig. $4 \mathrm{~b}, \mathrm{e}, \mathrm{h}$ and $\mathrm{k})$. This field is also heavily concentrated in areas dominated by biomass burning (e.g., central Africa) and sulfate aerosol (e.g., Europe, Southeast Asia, and North America).

Unraveling the contributions of aerosol parameters to $\Delta N_{\mathrm{d}}$ from different variables casts light on the diverging parameterization response over specific regions. Figure $4 \mathrm{e}, \mathrm{h}, \mathrm{b}$ and $\mathrm{k}$ show that $\left(\Delta N_{\mathrm{d}}\right)_{v_{\mathrm{a}}}$ has a markedly different response for ARG/ARG $\alpha$ and FN/FN-IL parameterizations. Over con- tinental areas, when ARG or ARG $\alpha$ is used, $\left(\Delta N_{\mathrm{d}}\right)_{v_{\mathrm{a}}}$ is much higher as compared with simulations with either FN or FN-IL. This is in fact a consequence of the two-fold stronger sensitivity of $N_{\mathrm{d}}$ to $d_{\mathrm{g}_{i}}$ exhibited by ARG and $\mathrm{ARG} \alpha$. This markedly stronger sensitivity to $v_{\mathrm{a}_{i}}$ is magnified in regions where aerosol changes are dominated by condensible species, and largely explains the higher $N_{\mathrm{d}}$ and $\Delta N_{\mathrm{d}}$ over Southeast Asia observed in Fig. 1. This region is particularly important in controlling the strength of the AIE, particularly through the impact it has on liquid water path.

Figure $4 \mathrm{c}, \mathrm{f}, \mathrm{i}$ and 1 show $\left(\Delta N_{\mathrm{d}}\right)_{\kappa_{\mathrm{a}}}$ for the different parameterizations, indicating that chemical composition effects represent a weak contribution to $\Delta N_{\mathrm{d}}$ from pre-industrial times.

\subsection{Sensitivity of CDNC to hygroscopicity parameter of organic aerosol}

The adjoint of the activation scheme can be used to estimate the envelope of uncertainty in $N_{\mathrm{d}}$ associated with parametric uncertainty. We focus here on the hygroscopicity parameter of organic aerosol species, and estimate the geographic imprint of its uncertainty on $N_{\mathrm{d}}$. The first-order derivative of $N_{\mathrm{d}}$ with respect to $\kappa_{\alpha}$ of any species can be calculated from Eq. (1) as

$$
\frac{\partial N_{\mathrm{d}}}{\partial \kappa_{\alpha}}=\sum_{i}\left(\frac{\partial N_{\mathrm{d}}}{\partial \kappa_{\mathrm{a}_{i}}}\right) \frac{\partial \kappa_{\mathrm{a}_{i}}}{\partial \kappa_{\alpha}}=\sum_{i}\left(\frac{\partial N_{\mathrm{d}}}{\partial \kappa_{\mathrm{a}_{i}}}\right) v_{\alpha, i} .
$$




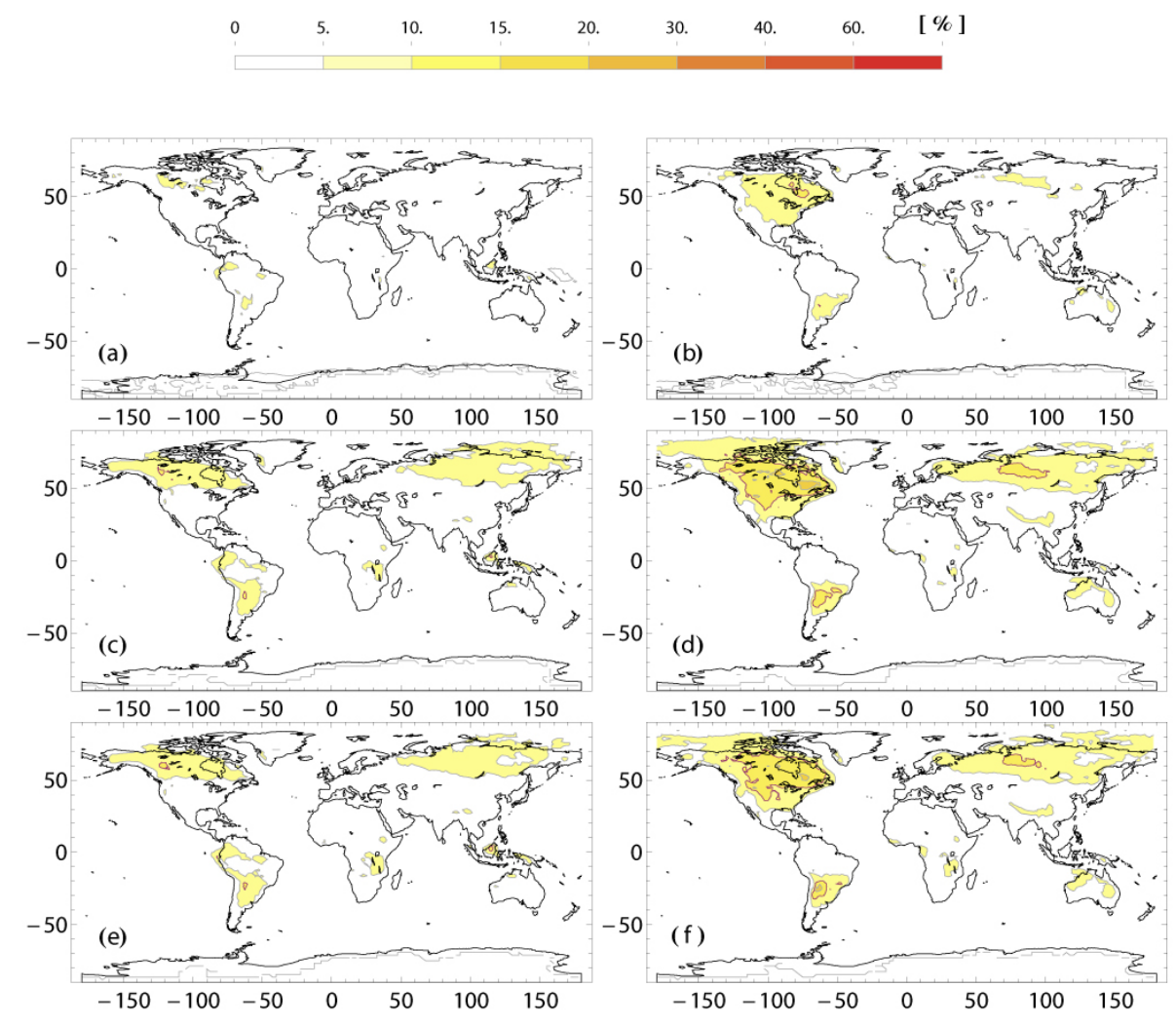

Fig. 5. Estimated percent uncertainty on $N_{\mathrm{d}}$ due to a $\pm 50 \%$ uncertainty in the hygroscopicity parameter of SOA for (a) ARG $\alpha$-PD, (b) ARG $\alpha$-PI, (c) FN-PD, (d) FN-PI, (e) FN-IL-PD, and (f) FN-IL-PI.

Then, the uncertainty in $N_{\mathrm{d}}$ associated with $\kappa_{\alpha}$ can be estimated, to first order, as

$\left(\delta N_{\mathrm{d}}\right)_{\kappa_{\alpha}} \approx \frac{\partial N_{\mathrm{d}}}{\partial \kappa_{\alpha}} \delta \kappa_{\alpha}$,

where $\delta \kappa_{\alpha}$ is the uncertainty in $\kappa_{\alpha}$. The assumed hygroscopicity of SOA and POM of $\kappa_{\text {soa }}=0.14$ and $\kappa_{\text {pom }}=0.1$ respectively (Table 1); however, there is a wide range of values reported for these parameters in the literature (e.g., Lathem et al., 2013). For application of Eq. (6), we investigated the impact on CDNC of a $\pm 50 \%$ uncertainty range in $\kappa_{\alpha}$. This uncertainty range has been utilized in previous modeling studies (e.g., Liu and Wang, 2010). The resulting fields (Fig. 5) indicate the regions where the uncertainty of the assumed hygroscopicity for organic matter impacts the CDNC the most.

For SOA, the annual-average percent CDNC uncertainty was $5.1 \%$ over continents for PD, and $7.8 \%$ for PI simulations. The percentages are negligible over oceanic regions averaging less than $0.5 \%$ in all cases. For the PD simulations, the uncertainty can be as large as $15 \%$ over continents, while for PI it can be up to $30 \%$ over the boreal forests owning to the large contribution of organics to aerosol volume in pre-industrial conditions. The uncertainty associated with the hygroscopicity of POM is smaller compared to that of SOA, with annual-average CDNC uncertainty over continents of $2.5 \%(3.5 \%)$ for the PD (PI) simulation, while reaching a maximum of $16 \%(22 \%)$ for the corresponding PD (PI) simulations. These results agree qualitatively with previous work focused on $\mathrm{CCN}$ uncertainty associated with perturbed parametric values (Liu and Wang, 2010).

Equation (6) only includes the effects of uncertainty during the step of aerosol activation. It does not account for other changes in CDNC associated with the modified hygroscopicity. For instance, an increase (decrease) in hygroscopicity might also increase (decrease) the rate of wet removal, reducing (augmenting) the total aerosol burden and having a corresponding impact on CDNC. Therefore, the uncertainties presented here are an upper limit for $\partial N_{\mathrm{d}} / \partial \kappa_{\alpha}$.

\section{Summary and conclusions}

The sensitivity of cloud droplet number concentration to aerosol properties was evaluated in a state-of-the-art GCM by using an adjoint sensitivity approach. Two commonly used parameterization frameworks - the ARG (Abdul-Razzak and Ghan, 2000) and FN (Fountoukis and Nenes, 2005) were tested and compared within the CAM5.1 GCM. All the parameterizations considered here showed a consistent sensitivity to accumulation mode aerosol number for both 
marine and continental aerosol. Furthermore, these sensitivities agreed to within $\pm 10 \%$ when compared to detailed numerical simulations of the activation process. Overall, the parameterizations also showed consistent responses to the updraft velocity. Both these variables are central in the determination of $N_{\mathrm{d}}$.

Inconsistent responses to the coarse mode aerosol properties were found across parameterizations, ranging from an overrepresentation of the water depletion of coarse mode particles in $\mathrm{ARG} \alpha$, to a lack of sensitivity to large particles in FN. The FN-IL, which includes the water uptake by inertially limited CCN, captures the sensitivity to coarse mode aerosol more accurately than the other schemes considered in this study. Although not a significant contributor to $N_{\mathrm{d}}$, the large amount of water vapor depleted by the coarse mode particles can modulate the magnitude of $\mathrm{d} N_{\mathrm{d}} / \mathrm{d} n_{\mathrm{a}}$. In fact, the consistently lower $N_{\mathrm{d}}$ over oceans predicted by $\mathrm{ARG} \alpha$ compared to FN and FN-IL is due to the large sensitivity to coarse mode particles. The diverse response observed across parameterizations implies that a physically consistent representation of coarse mode aerosol remains a challenge for activation parameterizations. A recently developed modification of FN addresses this issue by using an approximation specifically designed to correctly determine the rate of water uptake by the largest particles in the aerosol population (Morales and Nenes, 2014).

Although great emphasis in the literature has been placed on ensuring that activation parameterizations capture $\mathrm{d} N_{\mathrm{d}} / \mathrm{d} n_{\mathrm{a}}$ consistently, our study suggests that sensitivity to aerosol number alone does not capture the full extent of aerosol indirect effects, and does not explain the differences in $N_{\mathrm{d}}$ fields produced with these parameterizations. We found that the sensitivity of $N_{\mathrm{d}}$ to the geometric mean diameter, $d_{\mathrm{g}_{i}}$, was on average twofold higher for ARG compared to FN and FN-IL. This sensitivity difference accounts for the much larger $N_{\mathrm{d}}$ concentration predicted with $\mathrm{ARG} \alpha$ over heavily polluted environments. This is particularly noticeable over Southeast Asia, a region that also has very deep clouds. Therefore, large increases in $N_{\mathrm{d}}$ over that region have a profound impact on LWP, and therefore over shortwave cloud forcing. These two factors (i.e., the large change in $N_{\mathrm{d}}$ that induces a large change in LWP over Southeast Asia, the Maritime continent and the North Pacific) have been shown to control the strength of the indirect effects on CAM to a large extent (Wang et al., 2011).
The sensitivity analysis reaffirms the well-known importance of accumulation mode aerosol number concentration in controlling cloud droplet number concentrations. It was found that the variables controlling the size distribution of aerosol contribute the most to changes in CDNC between present-day and pre-industrial simulations. For the conditions commonly found in stratiform clouds simulated by CAM, aerosol number and size plays a much more important role than the chemical composition of the aerosol. However, the disproportionately large impact of coarse mode particles in modulating the overall sensitivity to aerosol changes, in particular over the oceans, has been in general overlooked and was brought forward in this study.

The adjoint sensitivities were further used in this study to unravel the regional footprint of specific aerosol species to $N_{\mathrm{d}}$. The large impact of primary organic matter (POM) in controlling accumulation mode number concentration was shown to also control the magnitude of the changes in $N_{\mathrm{d}}$ over large areas of the planet. This indicates that, given their considerable impact on both aerosol and CDNC, efforts should be made to constrain the uncertainty in emission sizes for these primary particles.

Computation of the regional distribution of $N_{\mathrm{d}}$ sensitivities to aerosol size distribution, chemical composition, and dynamic parameters is an important step in understanding the relative contribution of aerosol parameters to CDNC variability. We demonstrate this using the adjoint sensitivities to attribute the contribution from different aerosol properties to the change in $N_{\mathrm{d}}$ between present-day and pre-industrial simulations. Not surprisingly, changes in aerosol number, to a large extent, control the changes in $N_{\mathrm{d}}$, followed by change in mass and, to a lesser extent, changes in the hygroscopicity of aerosol. Overall, the computationally inexpensive information from adjoint analysis was shown to improve our understanding of what causes differences in model responses from each activation scheme.

Acknowledgements. We thank the DOE EaSM program for funding that supported the research carried out in this study. Authors would like to thank Xiaohong Liu for providing access to the computational resources. All the simulations for this work were performed with resources from the National Energy Research Scientific Computing Center (NERSC) of the US Department of Energy.

Edited by: V.-M. Kerminen 


\section{Appendix A}

\section{Adjoint development}

The method to compute the number of activated cloud droplets, $N_{\mathrm{d}}$, in both parameterizations considered here involves two conceptual steps. The first step is the computation of the $\mathrm{CCN}$ spectrum, i.e., the cumulative number of particles with critical supersaturation less than a given value $s$. The second step consists of determining the maximum supersaturation, $s_{\max }$, that develops in an ascending air parcel that rises with updraft velocity, $w$, and includes the water vapor condensation sink provided by the CCN computed in the previous step. The first step is achieved by mapping the aerosol size distribution and chemical composition onto supersaturation space (e.g., Fountoukis and Nenes, 2005; Karydis et al., 2012b), i.e.,

$N_{\mathrm{CCN}}(s)=\sum_{i}^{n_{m}} \frac{n_{\mathrm{a}_{i}}}{2}\left[1-\operatorname{erf}\left(u_{i}(s)\right)\right]$,

where

$u_{i}=\frac{2 \ln \left(s_{\mathrm{m}_{i}} / s\right)}{3 \sqrt{2} \ln \sigma_{\mathrm{g}_{i}}}$

and $s_{\mathrm{m}_{i}}$ is the critical supersaturation for a particle with a size equal to $d_{\mathrm{g}_{i}}$ and hygroscopicity parameter $\kappa_{i}, s_{\mathrm{m}_{i}}=$ $\frac{2}{\sqrt{\kappa_{i}}}\left(\frac{A}{3 d_{\mathrm{pg}_{i}}}\right)^{3 / 2}$. Equations (A1) and (A2) consider only Köhler theory for computation of CCN. The impact of water adsorption onto insoluble particles such as dust can also be treated with a similar formalism (Kumar et al., 2009). The second step is achieved by finding an approximate solution to the equation describing the supersaturation tendency in the ascending air parcel, which can be written as

$$
\left(\frac{\mathrm{d} q}{\mathrm{~d} t}\right)_{s_{\max }}=\frac{\alpha w}{\gamma} \text {. }
$$

Equation (A3) expresses the moment where $s_{\max }$ is attained in the parcel where the production and depletion of water vapor attained in the ascending air parcel is in balance. Production is due to the adiabatic expansion cooling provided by the cloud updraft, $\alpha w / \gamma$, and the depletion of supersaturation by condensation on the growing droplets, $(\mathrm{d} q / \mathrm{d} t)$. Once $s_{\max }$ is determined from Eq. (A3), the number of activated droplets is given by the CCN spectra evaluated at $s=s_{\max }$,

$N_{\mathrm{d}}=N_{\mathrm{CCN}}\left(s_{\max }\right)$.

The two parameterizations differ in the approximations made in the solution of Eq. (A3). An in-depth analysis of these assumptions can be found in Ghan et al. (2011). The ARG is constructed by performing a statistical fit to a large set of detailed numerical solutions to this equation, while the FN uses the "population splitting" approach, which brings Eq. (A3) to a form where an iterative numerical solution can be found for $s_{\max }$.

\section{A1 FN and FN-IL parameterizations}

The development of the adjoint of the Fountoukis and Nenes (2005) parameterization (FN), as well as that for the adsorption activation parameterization of Kumar et al. (2009), is described in full detail in Karydis et al. (2012b). Briefly, because the computation of $N_{\mathrm{d}}$ in $\mathrm{FN}$ is achieved by iterative solution of Eq. (A3), the computation of the sensitivities has to be achieved by performing a line-by-line differentiation of the numerical routines. Karydis et al. (2012b) used the automatic differentiation software TAPENADE to construct the routines necessary for efficient computation of derivatives. The FN-adjoint built with this procedure yields the set of sensitivities of $N_{\mathrm{d}}$ with analytical precision, and the computational cost of the computation is a constant multiple, independent of the number of input parameters, of the cost of computing $N_{\mathrm{d}}$.

\section{A2 ARG and ARG $\alpha$ parameterizations}

The ARG droplet activation parameterization (Abdul-Razzak et al., 1998; Abdul-Razzak and Ghan, 2000) computes the maximum supersaturation, $s_{\max }$, and droplet number concentration, $N_{\mathrm{d}}$, explicitly as a function of the updraft velocity, $w$, the aerosol size distribution parameters, $\sigma_{\mathrm{g}_{i}}$ and $d_{\mathrm{g}_{i}}, n_{\mathrm{a}_{i}}$, and chemical composition of the aerosol, represented by $\kappa_{\mathrm{a}_{i}}$. In this parameterization, $s_{\max }$ is given by

$$
\begin{aligned}
& s_{\max }= \\
& \left\{\sum_{i}^{n_{m}} \frac{1}{s_{\mathrm{m}_{i}}^{2}}\left[f_{1, i}\left(\frac{\zeta_{i}}{\eta_{i}}\right)^{3 / 2}+f_{2, i}\left(\frac{s_{\mathrm{m}_{i}}^{2}}{\eta_{i}+3 \zeta_{i}}\right)^{3 / 4}\right]\right\}^{-1 / 2},
\end{aligned}
$$

where $f_{1, i}$ and $f_{2, i}$ are functions of $\sigma_{\mathrm{g}_{i}}$ only. The explicit functionality of $f_{1, i}$ and $f_{2, i}$, together with the definitions of $\zeta_{i}$ and $\eta_{i}$, can be found in Abdul-Razzak and Ghan (2000). Because Eq. (A5) is an explicit function of the input variables, it is amenable for the calculation of analytical expressions for its derivatives. In this section we follow the approach of Rissman et al. (2004), and expand these expressions to include other parameters. The derivatives of $N_{\mathrm{d}}$ to a parameter $\chi_{j}$ read

$\frac{\partial N_{\mathrm{d}}}{\partial \chi_{j}}=\frac{\partial N_{\mathrm{CCN}}}{\partial \chi_{j}}-\sum_{i} \frac{\partial u_{i}}{\partial \chi_{j}}\left(\frac{n_{\mathrm{a}_{i}}}{\sqrt{\pi}} e^{-u_{i}^{2}}\right)$.

The term $\partial N_{\mathrm{CCN}} / \partial \chi_{j}$ is zero for all variables except for $\chi_{j}=n_{\mathrm{a}_{j}}$, for which case it is equal to $\left[1-\operatorname{erf}\left(u_{i}\right)\right] / 2$. The 
partial derivatives of $u_{i}$ read

$$
\begin{aligned}
\frac{\partial u_{i}}{\partial w} & =-\frac{\sqrt{2}}{3 s_{\max }}\left(\ln \sigma_{\mathrm{g}_{i}}\right)^{-1} \frac{\partial s_{\max }}{\partial w} \\
\frac{\partial u_{i}}{\partial n_{\mathrm{a}_{j}}} & =-\frac{\sqrt{2}}{3 s_{\max }}\left(\ln \sigma_{\mathrm{g}_{i}}\right)^{-1} \frac{\partial s_{\max }}{\partial n_{\mathrm{a}_{j}}} \\
\frac{\partial u_{i}}{\partial \kappa_{\mathrm{a}_{j}}} & =-\frac{\sqrt{2}}{3 s_{\max }}\left(\ln \sigma_{\mathrm{g}_{i}}\right)^{-1}\left(\frac{s_{\max }}{2 \kappa_{\mathrm{a}_{i}}} \delta_{i j}+\frac{\partial s_{\max }}{\partial \kappa_{\mathrm{a}_{j}}}\right) \\
\frac{\partial u_{i}}{\partial d_{\mathrm{g}_{j}}} & =-\frac{\sqrt{2}}{3 s_{\max }}\left(\ln \sigma_{\mathrm{g}_{i}}\right)^{-1}\left(\frac{3 s_{\max }}{2 d_{\mathrm{g}_{i}}} \delta_{i j}+\frac{\partial s_{\max }}{\partial d_{\mathrm{g}_{j}}}\right) \\
\frac{\partial u_{i}}{\partial \sigma_{\mathrm{g}_{j}}} & =-\frac{\sqrt{2}}{3 s_{\max }}\left(\ln \sigma_{\mathrm{g}_{i}}\right)^{-1}\left(\frac{3 s_{\max } u_{i}}{\sqrt{2} \sigma_{\mathrm{g}_{i}}} \delta_{i j}+\frac{\partial s_{\max }}{\partial \sigma_{\mathrm{g}_{j}}}\right),
\end{aligned}
$$

where $\delta_{i j}=0$ for $i \neq j$, and $\delta_{i j}=1$ for $i=j$. Defining the following functions as

$$
\begin{aligned}
& k_{i}=f_{1, i}\left(\frac{\zeta_{i}}{\eta_{i}}\right)^{3 / 2} \\
& g_{i}=f_{2, i}\left(\frac{s_{\mathrm{m}_{i}}^{2}}{\eta_{i}+3 \zeta_{i}}\right)^{3 / 4},
\end{aligned}
$$

the gradient of $s_{\max }$ can be written as

$$
\begin{aligned}
\frac{\partial s_{\max }}{\partial w} & =\frac{3}{4} \frac{s_{\max }^{3}}{w} \sum_{i} \frac{1}{s_{\mathrm{m}_{i}}^{2}}\left(k_{i}+\frac{3 g_{i}}{4} \frac{\eta_{i}+\zeta_{i}}{\eta_{i}+3 \zeta_{i}}\right) \\
\frac{\partial s_{\max }}{\partial n_{\mathrm{a}_{i}}} & =-\frac{3}{4 n_{\mathrm{a}_{i}}} \frac{s_{\max }^{3}}{s_{\mathrm{m}_{i}}^{2}}\left(k_{i}+\frac{g_{i}}{2} \frac{\eta_{i}}{\eta_{i}+3 \zeta_{i}}\right) \\
\frac{\partial s_{\max }}{\partial \kappa_{\mathrm{a}_{i}}} & =-\frac{1}{2 \kappa_{\mathrm{a}_{i}}} \frac{s_{\max }^{3}}{s_{\mathrm{m}_{i}}^{2}}\left(k_{i}+\frac{g_{i}}{4}\right) \\
\frac{\partial s_{\max }}{\partial d_{\mathrm{g}_{i}}} & =-\frac{3}{2 d_{\mathrm{g}_{i}}} \frac{s_{\max }^{3}}{s_{\mathrm{m}_{i}}^{2}}\left(k_{i}+\frac{g_{i}}{4}\right) \\
\frac{\partial s_{\max }}{\partial \sigma_{\mathrm{g}_{i}}} & =-\frac{5}{2 \sigma_{\mathrm{g}_{i}}} \frac{s_{\max }^{3} \ln \left(\sigma_{\mathrm{g}_{i}}\right)}{s_{\mathrm{m}_{i}}^{2}}\left(k_{i}+\frac{g_{i}}{4}\right) .
\end{aligned}
$$

\section{A2.1 Extension of ARG and its derivatives to account for non-continuum effects}

Ghan et al. (2011) extended the ARG parameterization to account for non-continuum effects through the inclusion of a size-dependent mass transfer coefficient $G$, which has explicit dependence on the mass accommodation coefficient $\alpha_{\mathrm{c}}$. In such a way, the transfer coefficient, $G_{i}$, is defined as

$G_{i}=G_{0} \frac{G\left(D_{\mathrm{pc}_{i}}, \alpha_{\mathrm{c}}\right)}{G\left(D_{\mathrm{pc}_{i}}, 1\right)}$,

where $G_{0}$ is the mass transfer coefficient for the continuum regime, which is used in the default ARG parameterization, and $G\left(x, \alpha_{\mathrm{c}}\right)$ is the size-dependent mass transfer coefficient (e.g., Pruppacher and Klett, 1997). $D_{\mathrm{pc}_{i}}$ is the critical wet diameter corresponding to $d_{\mathrm{g}_{i}}$. From Eq. (A10) it can be seen that, for $\alpha_{\mathrm{c}}=1, G_{i}=G_{0}$, and therefore $\mathrm{ARG} \alpha$ is identical to ARG for that case. The derivatives with respect to $d_{\mathrm{g}_{i}}$ and $\kappa_{\mathrm{a}_{i}}$ are affected by the redefinition of $G$ according to Eq. (A10). Since $N_{\mathrm{d}}$ now depends on $\alpha_{\mathrm{c}}$, the corresponding sensitivities can also be computed. The derivatives of $s_{\max }$ are as follows:

$$
\begin{aligned}
& \frac{\partial s_{\max }}{\partial \kappa_{\mathrm{a}_{i}}}= \\
& -\frac{1}{2 \kappa_{\mathrm{a}_{i}}} \frac{s_{\max }^{3}}{s_{\mathrm{m}_{i}}^{2}}\left[\left(k_{i}+\frac{g_{i}}{4}\right)+\frac{3 \Psi_{i}}{16}\left(k_{i}+\frac{3 g_{i}}{4} \frac{\eta_{i}+\zeta_{i}}{\eta_{i}+3 \zeta_{i}}\right)\right] \\
& \frac{\partial s_{\max }}{\partial d_{\mathrm{g}_{i}}}= \\
& -\frac{3}{2 d_{\mathrm{g}_{i}}} \frac{s_{\max }^{3}}{s_{\mathrm{m}_{i}}^{2}}\left[\left(k_{i}+\frac{g_{i}}{4}\right)+\frac{3 \Psi_{i}}{16}\left(k_{i}+\frac{3 g_{i}}{4} \frac{\eta_{i}+\zeta_{i}}{\eta_{i}+3 \zeta_{i}}\right)\right] .
\end{aligned}
$$

This extension also allows for the calculation of the sensitivities of $s_{\max }$ and $N_{\mathrm{d}}$ to the mass accommodation coefficient, $\alpha_{\mathrm{c}}$. The corresponding sensitivities are given by

$\frac{\partial s_{\max }}{\partial \alpha_{\mathrm{c}}}=-\frac{3}{16} \frac{s_{\max }^{3}}{\alpha_{\mathrm{c}}} \sum_{i} \frac{\Upsilon_{i}}{s_{\mathrm{m}_{i}}^{2}}\left(k_{i}+\frac{3 g_{i}}{4} \frac{\eta_{i}+\zeta_{i}}{\eta_{i}+3 \zeta_{i}}\right)$

and

$\frac{\partial u_{i}}{\partial \alpha_{\mathrm{c}}}=-\frac{\sqrt{2}}{3 s_{\max }}\left(\ln \sigma_{\mathrm{g}_{i}}\right)^{-1} \frac{\partial s_{\max }}{\partial \alpha_{\mathrm{c}}}$.

The coefficients $\Upsilon_{i}$ and $\Psi_{i}$ are defined as

$\Psi_{i}=K_{i} G_{i}\left(D_{\mathrm{pc}_{i}}, \alpha_{\mathrm{c}}\right)\left(1-\alpha_{\mathrm{c}} \frac{G_{0}}{G_{i}}\right)$

and

$\Upsilon_{i}=K_{i} G_{i}\left(D_{\mathrm{pc}_{i}}, \alpha_{\mathrm{c}}\right)$

where the function $K_{i}$ is a temperature-dependent coefficient given by

$K_{i}=\frac{2 \rho_{\mathrm{w}} R T}{e_{\mathrm{s}} M_{\mathrm{w}} \alpha_{\mathrm{c}} D_{\mathrm{pc}_{i}}}\left(\frac{2 \pi M_{\mathrm{w}}}{R T}\right)^{1 / 2}$.

In the previous expression $T$ is the temperature, $\rho_{\mathrm{w}}$ the density of water, $M_{\mathrm{w}}$ the molecular weight of water, $R$ the universal gas constant, and $e_{\mathrm{S}}$ the saturation vapor pressure of water at temperature $T$.

\section{Appendix B}

\section{Validation of parameterization derivatives}

The accuracy of the first-order derivatives of FN and ARG introduced in Appendix A has been extensively tested by comparing them against central difference computations (e.g., 
Table B1. Relative error for $N_{\mathrm{d}}, s_{\max }$, and the adjoint sensitivities $\partial N_{\mathrm{d}} / \partial \chi_{j}$, computed with the adjoint of the activation parameterizations, as compared against numerical parcel model values. Reported values correspond to the mean and the standard deviation of the percent error.

\begin{tabular}{llccc}
\hline Sensitivity & Aerosol mode & ARG $\alpha$ & FN & FN-IL \\
& & & & \\
\hline$N_{\mathrm{d}}$ & & $-18.1 \pm 9.7 \%$ & $8.1 \pm 7.7 \%$ & $-10.5 \pm 6.2 \%$ \\
$S_{\mathrm{max}}$ & & $-42.3 \pm 13 \%$ & $31 \pm 22.2 \%$ & $-24 \pm 6.7 \%$ \\
\hline \multirow{2}{*}{$\partial N_{\mathrm{d}} / \partial n_{\mathrm{a}_{i}}$} & Aitken & $-93 \pm 38 \%$ & $56 \pm 81 \%$ & $-57 \pm 16.6 \%$ \\
& Accumulation & $10.6 \pm 24 \%$ & $3.5 \pm 18 \%$ & $-8.1 \pm 20.4 \%$ \\
& Coarse & $-509 \pm 838 \%$ & $210 \pm 225 \%$ & $-93 \pm 131 \%$ \\
\hline $\mathrm{d} N_{\mathrm{d}} / \mathrm{d} n_{\mathrm{a}}$ & & $-15.6 \pm 8.8 \%$ & $+9.3 \pm 19 \%$ & $-19.4 \pm 15 \%$ \\
\hline \multirow{2}{*}{$\partial N_{\mathrm{d}} / \partial \kappa_{\mathrm{a}_{i}}$} & Aitken & $-74 \pm 18 \%$ & $27 \pm 53 \%$ & $-48 \pm 20 \%$ \\
& Coarse & $-300 \pm 223 \%$ & $100 \pm 0 \%$ & $-59 \pm 51 \%$ \\
\hline \multirow{2}{*}{$\partial N_{\mathrm{d}} / \partial d_{\mathrm{g}_{i}}$} & Aitken & $-74 \pm 18 \%$ & $27 \pm 53 \%$ & $-42 \pm 20 \%$ \\
& Accumulation & $191 \pm 348 \%$ & $96 \pm 216 \%$ & $96 \pm 216 \%$ \\
\hline$\partial N_{\mathrm{d}} / \partial w$ & Coarse & $-297 \pm 214 \%$ & $100 \pm 0 \%$ & $-64 \pm 52 \%$ \\
\hline
\end{tabular}
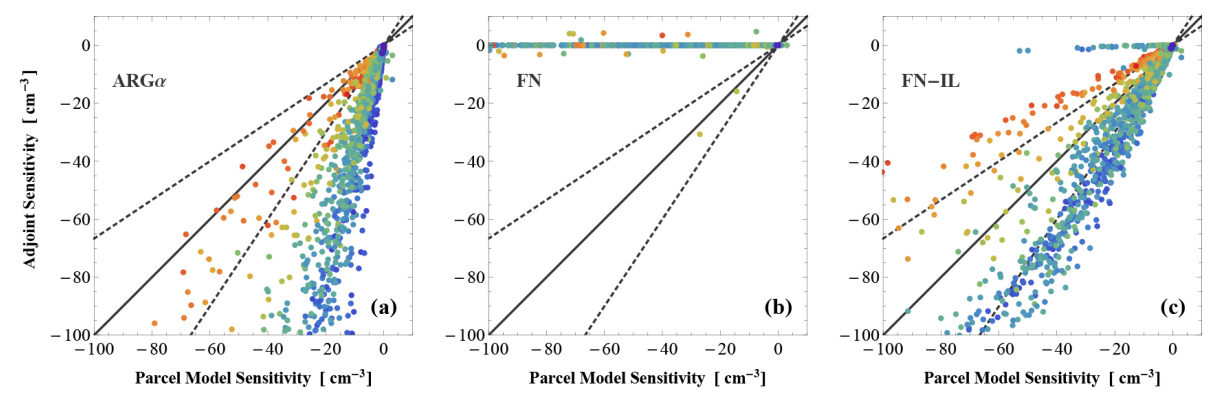

Fig. B1. Comparison between the sensitivity to hygroscopicity for coarse mode aerosol, $\partial N_{\mathrm{d}} / \partial \kappa_{\mathrm{a}_{i}}\left(\mathrm{~cm}^{-3}\right)$, computed with detailed parcel model simulations and (a) $\mathrm{ARG} \alpha$, (b) FN, and (c) FN-IL.

Karydis et al., 2012b). In this section however, we perform an evaluation of the adjoint sensitivities against detailed numerical simulations of the activation process, since this provides a method for validating the physical consistency of the parameterization-derived sensitivities.

Annual average fields of $n_{\mathrm{a}_{i}}, \kappa_{\mathrm{a}_{i}}, d_{\mathrm{g}_{i}}$ and $w$, corresponding to the $930 \mathrm{hPa}$ pressure level from a $6 \mathrm{yr}$ simulation with CAM5.1, were used to drive off-line computations with a Lagrangian parcel model. The Lagrangian parcel model used here explicitly computes the size-resolved growth of cloud droplets in a non-entraining parcel ascending with a constant updraft velocity (Pruppacher and Klett, 1997). The temporal evolution of supersaturation is also computed. The sensitivities were performed by central difference computation for each of the 10 variables (requiring of 20 model integrations per grid cell). Identical input was used to drive the adjoint sensitivities of ARG $\alpha, \mathrm{FN}$, and FN-IL. All the calculations were performed assuming an accommodation coefficient $\alpha_{\mathrm{c}}=0.1$ (Raatikainen et al., 2013).
The relative errors between the parcel model and parameterization-derived sensitivities are summarized in Table B1. The relative error $\epsilon_{\chi}$ for a quantity $\chi$ is defined here as

$\epsilon_{\chi}=1-\frac{\chi_{\mathrm{PM}}}{\chi_{\mathrm{param}}}$,

where $\chi_{\mathrm{PM}}$ and $\chi_{\text {param }}$ are the parcel model and parameterization-derived value for $\chi$ respectively. This analysis reveals that the accuracy of the derivatives fluctuates widely across the different variables considered. Among those sensitivities that are better captured by all the parameterizations are those of $N_{\mathrm{d}}$ to updraft, $\partial N_{\mathrm{d}} / \partial w$, accumulation mode number concentration, and total aerosol number $\mathrm{d} N_{\mathrm{d}} / \mathrm{d} n_{\mathrm{a}}$, which are all within $\pm 30 \%$ error. Similarly, all parameterizations capture $N_{\mathrm{d}}$ within a $\pm 20 \%$ margin, with $\mathrm{ARG} \alpha$ and FN-IL slightly underestimating $N_{\mathrm{d}}$ while FN shows the opposite trend, biasing $N_{\mathrm{d}} \sim 10 \%$ high. Table B1 reflects that the largest errors are encountered for coarse mode particles, with sensitivity of $N_{\mathrm{d}}$ to Aitken and 
accumulation mode having overall smaller biases than those of coarse mode characteristics.

It is apparent from this analysis that the largest discrepancies amongst parameterizations occur precisely for coarse mode characteristics. For instance, sensitivity of $N_{\mathrm{d}}$ to coarse mode aerosol characteristics is overpredicted by $300-500 \%$ for $\mathrm{ARG} \alpha$, while FN-IL reduces this overprediction to $\sim$ $100 \%$. On the other hand, the lack of responsiveness of $N_{\mathrm{d}}$ computed with FN to perturbations in coarse mode aerosol is made clear from the relative error of $100 \% \pm 0 \%$ observed for coarse mode $\kappa_{\mathrm{a}_{i}}$ and $d_{\mathrm{g}_{i}}$. For both these cases, the absolute value of the adjoint sensitivities is negligibly small. The variability associated with coarse mode characteristics is illustrated in Fig. B1 with the derivative of $N_{\mathrm{d}}$ to the hygroscopicity $\kappa_{\mathrm{a}_{i}}$.
Sensitivity to accumulation mode $\kappa_{\mathrm{a}_{i}}$ and $d_{\mathrm{g}_{i}}$ shows a large variability as measured by the standard deviation of the errors for all parameterizations, but the bias for the case of ARG $\alpha$ is a factor of 2 larger than it is for either FN or FN-IL. However, the large bias and considerable scatter for $\partial N_{\mathrm{d}} / \partial \kappa_{\mathrm{a}_{i}}$ and $\partial N_{\mathrm{d}} / \partial d_{\mathrm{g}_{i}}$ suggests that the parameterizations are not accurately capturing the dependency of $N_{\mathrm{d}}$ on those variables. 


\section{References}

Abdul-Razzak, H. and Ghan, S.: A parameterization of aerosol activation: 2. Multiple aerosol types, J. Geophys. Res., 105, 68376844, 2000.

Abdul-Razzak, H., Ghan, S., and Rivera-Carpio, C.: A parameterization of aerosol activation: 1. Single aerosol type, J. Geophys. Res., 103, 6123-6131, 1998.

Adams, P. J. and Seinfeld, J. H.: Disproportionate impact of particulate emissions on global cloud condensation nuclei concentrations, Geophys. Res. Lett., 30, 1239, doi:10.1029/2002GL016303, 2003.

Barahona, D., West, R. E. L., Stier, P., Romakkaniemi, S., Kokkola, H., and Nenes, A.: Comprehensively accounting for the effect of giant $\mathrm{CCN}$ in cloud activation parameterizations, Atmos. Chem. Phys., 10, 2467-2473, doi:10.5194/acp-10-2467-2010, 2010.

Bauer, S. E. and Menon, S.: Aerosol direct, indirect, semidirect, and surface albedo effects from sector contributions based on the IPCC AR5 emissions for preindustrial and present-day conditions, J. Geophys. Res., 117, D01206, doi:10.1029/2011JD016816, 2012.

Dentener, F., Kinne, S., Bond, T., Boucher, O., Cofala, J., Generoso, S., Ginoux, P., Gong, S., Hoelzemann, J. J., Ito, A., Marelli, L., Penner, J. E., Putaud, J.-P., Textor, C., Schulz, M., van der Werf, G. R., and Wilson, J.: Emissions of primary aerosol and precursor gases in the years 2000 and 1750 prescribed data-sets for AeroCom, Atmos. Chem. Phys., 6, 4321-4344, doi:10.5194/acp-64321-2006, 2006.

Dentener, F., Kinne, S., Bond, T., Boucher, O., Cofala, J., Generoso, S., Ginoux, P., Gong, S., Hoelzemann, J. J., Ito, A., Marelli, L., Penner, J. E., Putaud, J.-P., Textor, C., Schulz, M., van der Werf, G. R., and Wilson, J.: The Dynamical Core, Physical Parameterizations, and Basic Simulation Characteristics of the Atmospheric Component AM3 of the GFDL Global Coupled Model CM3, J. Climate, 24, 3484-3519, 2011.

Fountoukis, C. and Nenes, A.: Continued development of a cloud droplet formation parameterization for global climate models, J. Geophys. Res., 110, D11212, doi:10.1029/2004JD005591, 2005.

Ghan, S., Guzman, G., and Abdul-Razzak, H.: Competition between sea salt and sulfate particles as cloud condensation nuclei, J. Atmos. Sci., 55, 3340-3347, 1998.

Ghan, S., Abdul-Razzak, H., Nenes, A., Ming, Y., Liu, X., Ovchinnikov, M., Meskhidze, N., Xu, J., and Shi, X.: Droplet nucleation: physically-based parameterization and comparative evaluation, J. Adv. Model. Earth. Syst., 3, D10S30, doi:10.1029/2011MS000074, 2011.

Ghan, S. J., Liu, X., Easter, R. C., Zaveri, R., Rasch, P. J., and Yoon, J.-H.: Toward a Minimal Representation of Aerosols in Climate Models: Comparative Decomposition of Aerosol Direct, Semidirect, and Indirect Radiative Forcing, J. Climate, 25, 6461-6476, doi:10.1175/JCLI-D-11-00650.1, 2012.

Intergovernmental Panel on Climate Change: Fourth Assessment Report: Climate Change 2007: Working Group I Report: The Physical Science Basis, Geneva: IPCC, http://www.ipcc.ch/ ipccreports/ar4-wg1.htm, 2007.

Jimenez, J. L., Canagaratna, M. R., Donahue, N. M., Prevot, A. S. H., Zhang, Q., Kroll, J. H., DeCarlo, P. F., Allan, J. D., Coe, H., Ng, N. L., Aiken, A. C., Docherty, K. S., Ulbrich, I. M., Grieshop, A. P., Robinson, A. L., Duplissy, J., Smith, J. D., Wil- son, K. R., Lanz, V. A., Hueglin, C., Sun, Y. L., Tian, J., Laaksonen, A., Raatikainen, T., Rautiainen, J., Vaattovaara, P., Ehn, M., Kulmala, M., Tomlinson, J. M., Collins, D. R., Cubison, M. J., Dunlea, E. J., Huffman, J. A., Onasch, T. B., Alfarra, M. R., Williams, P. I., Bower, K., Kondo, Y., Schneider, J., Drewnick, F., Borrmann, S., Weimer, S., Demerjian, K., Salcedo, D., Cottrell, L., Griffin, R., Takami, A., Miyoshi, T., Hatakeyama, S., Shimono, A., Sun, J. Y., Zhang, Y. M., Dzepina, K., Kimmel, J. R., Sueper, D., Jayne, J. T., Herndon, S. C., Trimborn, A. M., Williams, L. R., Wood, E. C., Middlebrook, A. M., Kolb, C. E., Baltensperger, U., and Worsnop, D. R.: Evolution of organic aerosols in the atmosphere, Science, 326, 1525-1529, 2009.

Karydis, V. A., Capps, S. L., Moore, R. H., Russell, A. G., Henze, D. K., and Nenes, A.: Using a global aerosol model adjoint to unravel the footprint of spatially-distributed emissions on cloud droplet number and cloud albedo, Geophys. Res. Lett., 39, 90419055, 2012a.

Karydis, V. A., Capps, S. L., Russell, A. G., and Nenes, A.: Adjoint sensitivity of global cloud droplet number to aerosol and dynamical parameters, Atmos. Chem. Phys., 12, 9041-9055, doi:10.5194/acp-12-9041-2012, 2012 b.

Kinne, S., Schulz, M., Textor, C., Guibert, S., Balkanski, Y., Bauer, S. E., Berntsen, T., Berglen, T. F., Boucher, O., Chin, M., Collins, W., Dentener, F., Diehl, T., Easter, R., Feichter, J., Fillmore, D., Ghan, S., Ginoux, P., Gong, S., Grini, A., Hendricks, J., Herzog, M., Horowitz, L., Isaksen, I., Iversen, T., Kirkevåg, A., Kloster, S., Koch, D., Kristjansson, J. E., Krol, M., Lauer, A., Lamarque, J. F., Lesins, G., Liu, X., Lohmann, U., Montanaro, V., Myhre, G., Penner, J., Pitari, G., Reddy, S., Seland, O., Stier, P., Takemura, T., and Tie, X.: An AeroCom initial assessment - optical properties in aerosol component modules of global models, Atmos. Chem. Phys., 6, 1815-1834, doi:10.5194/acp-6-1815-2006, 2006.

Kumar, P., Sokolik, I. N., and Nenes, A.: Parameterization of cloud droplet formation for global and regional models: including adsorption activation from insoluble CCN, Atmos. Chem. Phys., 9, 2517-2532, doi:10.5194/acp-9-2517-2009, 2009.

Lamarque, J.-F., Bond, T. C., Eyring, V., Granier, C., Heil, A., Klimont, Z., Lee, D., Liousse, C., Mieville, A., Owen, B., Schultz, M. G., Shindell, D., Smith, S. J., Stehfest, E., Van Aardenne, J., Cooper, O. R., Kainuma, M., Mahowald, N., McConnell, J. R., Naik, V., Riahi, K., and van Vuuren, D. P.: Historical (1850-2000) gridded anthropogenic and biomass burning emissions of reactive gases and aerosols: methodology and application, Atmos. Chem. Phys., 10, 7017-7039, doi:10.5194/acp10-7017-2010, 2010.

Lathem, T. L., Beyersdorf, A. J., Thornhill, K. L., Winstead, E. L., Cubison, M. J., Hecobian, A., Jimenez, J. L., Weber, R. J., Anderson, B. E., and Nenes, A.: Analysis of CCN activity of Arctic aerosol and Canadian biomass burning during summer 2008, Atmos. Chem. Phys., 13, 2735-2756, doi:10.5194/acp-13-27352013, 2013.

Lee, L. A., Carslaw, K. S., Pringle, K. J., Mann, G. W., and Spracklen, D. V.: Emulation of a complex global aerosol model to quantify sensitivity to uncertain parameters, Atmos. Chem. Phys., 11, 12253-12273, doi:10.5194/acp-1112253-2011, 2011.

Lee, L. A., Carslaw, K. S., Pringle, K. J., and Mann, G. W.: Mapping the uncertainty in global $\mathrm{CCN}$ using emulation, At- 
mos. Chem. Phys., 12, 9739-9751, doi:10.5194/acp-12-97392012, 2012.

Lee, L. A., Pringle, K. J., Reddington, C. L., Mann, G. W., Stier, P., Spracklen, D. V., Pierce, J. R., and Carslaw, K. S.: The magnitude and causes of uncertainty in global model simulations of cloud condensation nuclei, Atmos. Chem. Phys., 13, 8879-8914, doi:10.5194/acp-13-8879-2013, $2013 \mathrm{a}$.

Lee, Y. H., Lamarque, J.-F., Flanner, M. G., Jiao, C., Shindell, D. T., Berntsen, T., Bisiaux, M. M., Cao, J., Collins, W. J., Curran, M., Edwards, R., Faluvegi, G., Ghan, S., Horowitz, L. W., McConnell, J. R., Myhre, G., Nagashima, T., Naik, V., Rumbold, S. T., Skeie, R. B., Sudo, K., Takemura, T., and Thevenon, F.: Evaluation of preindustrial to present-day black carbon and its albedo forcing from ACCMIP (Atmospheric Chemistry and Climate Model Intercomparison Project), Atmos. Chem. Phys., 13, 2607-2634, doi:10.5194/acp-13-2607-2013, 2013 b.

Liu, X. and Wang, J.: How important is organic aerosol hygroscopicity to aerosol indirect forcing?, Environ. Res. Lett., 5, 4, doi:10.1088/1748-9326/5/4/044010, 2010.

Liu, X., Easter, R. C., Ghan, S. J., Zaveri, R., Rasch, P., Shi, X., Lamarque, J.-F., Gettelman, A., Morrison, H., Vitt, F., Conley, A., Park, S., Neale, R., Hannay, C., Ekman, A. M. L., Hess, P., Mahowald, N., Collins, W., Iacono, M. J., Bretherton, C. S., Flanner, M. G., and Mitchell, D.: Toward a minimal representation of aerosols in climate models: Description and evaluation in the Community Atmosphere Model CAM5, Geosci. Model Dev., 5, 709-739, doi:10.5194/gmd-5-709-2012, 2012.

McFiggans, G., Artaxo, P., Baltensperger, U., Coe, H., Facchini, M. C., Feingold, G., Fuzzi, S., Gysel, M., Laaksonen, A., Lohmann, U., Mentel, T. F., Murphy, D. M., O’Dowd, C. D., Snider, J. R., and Weingartner, E.: The effect of physical and chemical aerosol properties on warm cloud droplet activation, Atmos. Chem. Phys., 6, 2593-2649, doi:10.5194/acp-6-25932006, 2006.

Ming, Y., Ramaswamy, V., Donner, L. J., and Phillips, V. T. J.: A new parameterization of cloud droplet activation applicable to general circulation models, J. Atmos. Sci., 63, 1348-1356, 2006.

Morales, R. and Nenes, A.: Droplet activation parameterization: The population splitting concept revisited, Geosci. Model Dev., submitted, 2014.

Morrison, H. and Gettelman, A.: A new two-moment bulk stratiform cloud microphysics scheme in the Community Atmosphere Model, Version 3 (CAM3). Part I: Description and numerical tests, J. Climate, 21, 3642-3659, doi:10.1175/2008JCLI2105.1, 2008.

Myhre, G., Samset, B. H., Schulz, M., Balkanski, Y., Bauer, S., Berntsen, T. K., Bian, H., Bellouin, N., Chin, M., Diehl, T., Easter, R. C., Feichter, J., Ghan, S. J., Hauglustaine, D., Iversen, T., Kinne, S., Kirkevåg, A., Lamarque, J.-F., Lin, G., Liu, X., Lund, M. T., Luo, G., Ma, X., van Noije, T., Penner, J. E., Rasch, P. J., Ruiz, A., Seland, Ø., Skeie, R. B., Stier, P., Takemura, T., Tsigaridis, K., Wang, P., Wang, Z., Xu, L., Yu, H., Yu, F., Yoon, J.-H., Zhang, K., Zhang, H., and Zhou, C.: Radiative forcing of the direct aerosol effect from AeroCom Phase II simulations, Atmos. Chem. Phys., 13, 1853-1877, doi:10.5194/acp-13-18532013, 2013.

Novakov, T. and Penner, J. E.: Large contribution of organic aerosols to cloud-condensation-nuclei concentrations, Nature, 365, 823-826, doi:10.1038/365823a0, 1993.
Petters, M. D. and Kreidenweis, S. M.: A single parameter representation of hygroscopic growth and cloud condensation nucleus activity, Atmos. Chem. Phys., 7, 1961-1971, 2007.

Pierce, J. R. and Adams, P. J.: Uncertainty in global CCN concentrations from uncertain aerosol nucleation and primary emission rates, Atmos. Chem. Phys., 9, 1339-1356, doi:10.5194/acp-91339-2009, 2009.

Pruppacher, H. and Klett, J.: Microphysics of clouds and precipitation, Atmospheric and oceanographic sciences library, Kluwer Academic Publishers, 2nd rev, and enl edn., 489 -510, 1997.

Quaas, J., Ming, Y., Menon, S., Takemura, T., Wang, M., Penner, J. E., Gettelman, A., Lohmann, U., Bellouin, N., Boucher, O., Sayer, A. M., Thomas, G. E., McComiskey, A., Feingold, G., Hoose, C., Kristjánsson, J. E., Liu, X., Balkanski, Y., Donner, L. J., Ginoux, P. A., Stier, P., Grandey, B., Feichter, J., Sednev, I., Bauer, S. E., Koch, D., Grainger, R. G., Kirkevåring;g, A., Iversen, T., Seland, Ø., Easter, R., Ghan, S. J., Rasch, P. J., Morrison, H., Lamarque, J.-F., Iacono, M. J., Kinne, S., and Schulz, M.: Aerosol indirect effects - general circulation model intercomparison and evaluation with satellite data, Atmos. Chem. Phys., 9, 8697-8717, doi:10.5194/acp-9-8697-2009, 2009.

Raatikainen, T., Nenes, A., Seinfeld, J. H., Morales, R., Moore, R. H., Lathem, T. L., Lance, S., Padro, L. T., Lin, J. J., Cerully, K. M., Bougiatioti, A., Cozic, J., Ruehl, C. R., Chuang, P. Y., Anderson, B. E., Flagan, R. C., Jonsson, H., Mihalopoulos, N., and Smith, J. N.: Worldwide data sets constrain the water vapor uptake coefficient in cloud formation, Proc. Nat. Acad. Sci., 110, 3760-3764, doi:10.1073/pnas.1219591110, 2013.

Reutter, P., Su, H., Trentmann, J., Simmel, M., Rose, D., Gunthe, S. S., Wernli, H., Andreae, M. O., and Pöschl, U.: Aerosol- and updraft-limited regimes of cloud droplet formation: influence of particle number, size and hygroscopicity on the activation of cloud condensation nuclei (CCN), Atmos. Chem. Phys., 9, 70677080, doi:10.5194/acp-9-7067-2009, 2009.

Rissman, T. A., Nenes, A., and Seinfeld, J. H.: Chemical amplification (dampening) of the Twomey effect: Conditions Derived from droplet activation, J. Atmos. Sci., 61, 919-930, 2004.

Saide, P. E., Carmichael, G. R., Spak, S. N., Minnis, P., and Ayers, J. K.: Improving aerosol distributions below clouds by assimilating satellite-retrieved cloud droplet number, Proc. Nat. Acad. Sci., 11945-11949, doi:10.1073/pnas.1205877109, 2012.

Shipway, B. and Abel, S.: Analytical estimation of cloud droplet nucleation based on an underlying aerosol population, Atmos. Res., 96, 344-355, doi:10.1016/j.atmosres.2009.10.005, 2010.

Stier, P., Feichter, J., Kinne, S., Kloster, S., Vignati, E., Wilson, J., Ganzeveld, L., Tegen, I., Werner, M., Balkanski, Y., Schulz, M., Boucher, O., Minikin, A., and Petzold, A.: The aerosol-climate model ECHAM5-HAM, Atmos. Chem. Phys., 5, 1125-1156, 2005 ,

http://www.atmos-chem-phys.net/5/1125/2005/.

Trivitayanurak, W. and Adams, P. J.: Does the POA-SOA split matter for global CCN formation?, Atmos. Chem. Phys., 14, 9951010, doi:10.5194/acp-14-995-2014, 2014.

Wang, M., Ghan, S., Ovchinnikov, M., Liu, X., Easter, R., Kassianov, E., Qian, Y., and Morrison, H.: Aerosol indirect effects in a multi-scale aerosol-climate model PNNL-MMF, Atmos. Chem. Phys., 11, 5431-5455, doi:10.5194/acp-11-54312011, 2011. 
Zhao, C., Liu, X., Qian, Y., Yoon, J., Hou, Z., Lin, G., McFarlane, S., Wang, H., Yang, B., Ma, P.-L., Yan, H., and Bao, J.: A sensitivity study of radiative fluxes at the top of atmosphere to cloudmicrophysics and aerosol parameters in the Community Atmosphere Model CAM5, Atmos. Chem. Phys., 13, 10969-10987, 2013. 